\title{
Oltu-Balkaya havzasının (KD Türkiye) tektonik konumu ve Geç Kretase sonrası jeolojik evrimi
}

\author{
Tectonic setting and structural evolution of post-Late Cretaceous \\ the Oltu-Balkaya basin (NE Turkey)
}

\author{
Hüseyin YILMAZ ${ }^{1}$ ve Ali YILMAZ ${ }^{2}$ \\ ${ }^{1}$ Cumhuriyet Üniversiesi, Mühendislik Fak., Jeofizik. Müh. Böl., 58140, Sivas, Türkiye. \\ hyilmaz44@gmail.com \\ ${ }^{2}$ Cumhuriyet Üniversitesi, Mühendislik Fak., Çevre Müh. Böl., 58140, Sivas, Türkiye.
}

\section{ÖZ}

Oltu-Balkaya havzası, Pontid Yayı ve Anadolu-Toros Platformu'nun arasında Üst Maastrihtiyen'den itibaren gelişen çarpışma (ilk çarpışma-soft-collision) ile oluşmaya başlamıştır ve Maastrihtiyen-Erken Eosen döneminde çarpışmalı bir önülke havzası olarak evrim geçirmiştir. Bu dönemde alttan üste doğru sırasıyla karbonat arakatkı1ı türbiditik karasal kırıntılılar, denizel delta çökelleri ve denizel kırıntılılar çökelmiştir.

Çarpışma evresini karakterize eden bu havza dolgusunun üzerine bir taban konglomerasıyla sı $\breve{g}$ denizel kırıntılı çökeller ve çarpışma sonrası magmatizmayla deneştirilebilecek yüksek potasyumlu volkaniklerden oluşan Orta-Geç Eosen yaşlı birimler gelmektedir. Eosen sonunda tümüyle su üstü olan bölgede (en son çarpışma-hard-final collision) Oligosen`de bölgesel bir transgresyonla Oligosen-Geç Miyosen zaman aralığında jips ve yüksek potasyumlu volkanik ara düzeyli karasal kırıntılılar ve sığ denizel birimlerden oluşan bir molas çökelmiştir. Bu dönemi karakterize eden istifin çökelmesinden sonra Miyosen ortalarında bölge sıkışarak tümüyle kara haline dönüşmüştür. Akarsu ortamından gölsel ortama kadar değişen bütünüyle karasal çökel ve volkanitlerden oluşan Geç Miyosen-Erken Pliyosen birimlerinde KB-GD doğrultulu KD ve GB ya eğimli normal faylar gözlenmektedir. Gerilmeli bir tektonik rejimi yansıtan bu dönemde yaygın andezitik ve dasitik volkanizma gerçekleşmiştir. Üst Pliyosen-Kuvaterner yaşta yarı pekişmiş karasal kırıntılı çökeller ise bu birimleri açısal uyumsuzlukla örtmektedir.

Oltu-Balkaya havzası yaklaşı KD-GB gidişli egemen kıvrımlanma ve yaklaşık $40^{\circ}$ ye varan kuzeye eğimli KD-GB doğrultulu bir bindirme fayı ile karakteristiktir. Bu yapılar, Maastrihtiyen'de başlayan çarpışmanın kesintisiz olarak en azından Oligosen-Miyosen süresince de havzada etkin olan KB-GD yönlü bir sıkışmalı tektonik rejimi simgelemektedir. Üst Pliyosen-Kuvaterner yaşlı kaya birimleri ise kıvrımlanmamış olup, Neotektonik dönemi yansıtmaktadır. 
Sonuç olarak, Oltu-Balkaya havzası, Maastrihtiyen-Erken Eosen döneminde çarpışma evresi, Orta EosenErken Pliyosen döneminde çarpışma sonrası ve Geç Pliyosen'den Günümüze kadar (Neotektonik dönem), doğrultu atımlı rejimin egemen olduğu üstüste gelişmiş bir havzayı temsil etmektedir.

Anahtar Kelimeler: Çarpışma, çarpışma sonrası, Oltu-Balkaya havzası, yapısal evrim

\section{ABSTRACT}

The Oltu-Balkaya basin has started to open by the collision (soft-collision) between Pontide Arc and Anatolide-Tauride Platform since late Maastrihtian and was evolved as collisional foreland basins during Upper Maastrihtian and Eocene time. At this period, turbiditic continental deposits intercalated with carbonates, marine deltaic deposits and marine detritics are deposited, from bottom to top, respectively.

Middle-Late Eocene shallow marin clastic deposits and high-K volcanics which may be attributed to post collisional magmatism lie on this basin fill characterizing the collisional phase. At the begining of Oligocene time, a molas consisting of continental clastics and shallow marine units with interlayeres of gypsum and high-K volcanics were deposited on a regional unconformity at the Oligocene-Late Miocene interval in the region which was a completely emergent land (hard-final collision) at the end of Eocene. After deposition of the sequence characterizing this period, the region has completely become a land in the Miocene time by compression. Normal faults with NW-SE striking and in the direction of NE - SW dipping are observed in Late Miocene-Early Pliocene units consisting of fluvial to lacustrine completely continental deposits and volcanics. A widespread andesitic and dasitic volcanism occured at this period reflecting an extensional tectonic regime. Late Pliocene-Quaternary semi-consolidated continental clastic deposits cover these units by ungular unconformity.

The Oltu-Balkaya basin is characterized by dominant folding with approximately NE-SW trending axis and a thrust fault striking NE-SW, which dips about $40^{\circ}$ northward. These structures as a whole represent $N W$-SW-directed compressional tectonic regime prevailed in the basin at least during Late OligoceneMiocene time. As for the Late Pliocene-Quaternary beds rest on an angular unconformity over the older units and this sequence which have not been folded represents Neotectonic period.

As a result, the Oltu-Balkaya basin represents a superimposed basin which is syn-collisional in Upper Maastrictian-Middle Eocene, post-collisional in Middle Eocene-Early Pliocene and where the strike-slipe regime dominant since the Late Pliocene to present time (Neotectonic Period).

Key Words: Collision, Oltu-Balkaya Basin, post-collision, structural evolution

\section{GIRIŞ̧}

İlk kez Lange (1967) tarafından adlandırılan OltuBalkaya havzası, Erzurum'un yaklaşık 100 km kuzeydoğusunda, yatay olarak yaklaşık $25 \mathrm{Km}$ eninde ve $50 \mathrm{Km}$ uzunluğunda bir havzadır (Şekil 1). KD-GB uzanımlı bu havza, çevresindeki temeli oluşturan kaya birimlerinin genel gidişine hemen hemen paraleldir. Oltu-Balkaya havzas1, Doğu Pontidler ve Anadolu-İran Platformu arasındaki kenet zonu üzerinde gelişmiş en önemli havzalardan biridir. Havza, bölgesel jeolojik çalışmaların (Baykal 1950; Erentöz, 1954; Gattinger, 1955; Altınl1, 1969; Erentöz ve Ketin, 1974) yanı sıra içerdiği kömür yatakları nedeniyle ekonomik amaçlı birçok araştırmanın konusu olmuştur (Lahn ve Romber, 1939; Tendam, 1951; Nebert, 1963a,b; Engin ve Engin, 1964; Lange, 1967; Wedding, 1956; Akalın, 1978; Özdemir, 1981). 
Bulut vd. (1989), Tortum-Narman-OltuOlur bölgesinin Tersiyer öncesi temel üzerinde uyumsuzlukla yer alan Eosen yaşlı denizel çökellerin yanısıra, bu istifin üzerinde OligoMiyosen yaşlı karasal çökellerin ve volkanitlerin de sira ile uyumsuzlukla yer aldıklarını ileri sürmektedirler. Bozkuş (1990) ve Bilgiç vd. (1995) Oltu-Balkaya havzasındaki Tersiyer yaşlı istifin ve Bozkuş (1998) Oltu'nun güneybatısındaki Narman dolayındaki Geç Mesozoyik-Tersiyer istifin stratigrafisini tanıtmaya çalışmışlardır. Yılmaz vd. (2000) bölgenin tektonik birliklerini değerlendirirken Oltu kuzeyini Doğu Pontidlerin yayönü havza ürünü olarak kabul ettikleri Bayburt-Karabağ ekay zonu, Oltu bölgesini ise Kuzey Anadolu-Küçük Kafkaslar Kenedi ürünleri olarak yorumlamışlardır. Konak vd. (2001) bölgenin 1/100.000 ölçekli jeoloji harita alımını gerçekleştirmiş ve Konak ve Hakyemez (2008) bu çalışmaya dayalı olarak Oltu-Balkaya havzasını, kuzeybatıdan güneydoğuya (?) itilmiş Kışla Metamorfiti, Çardaklı Birliği ve güneydoğudan kuzeybatıya itilmiş Erzurum-Kars Ofiyolit Zonu arasında oluşmuş Tersiyer yaşlı bir havza olarak yorumlamışlardır.

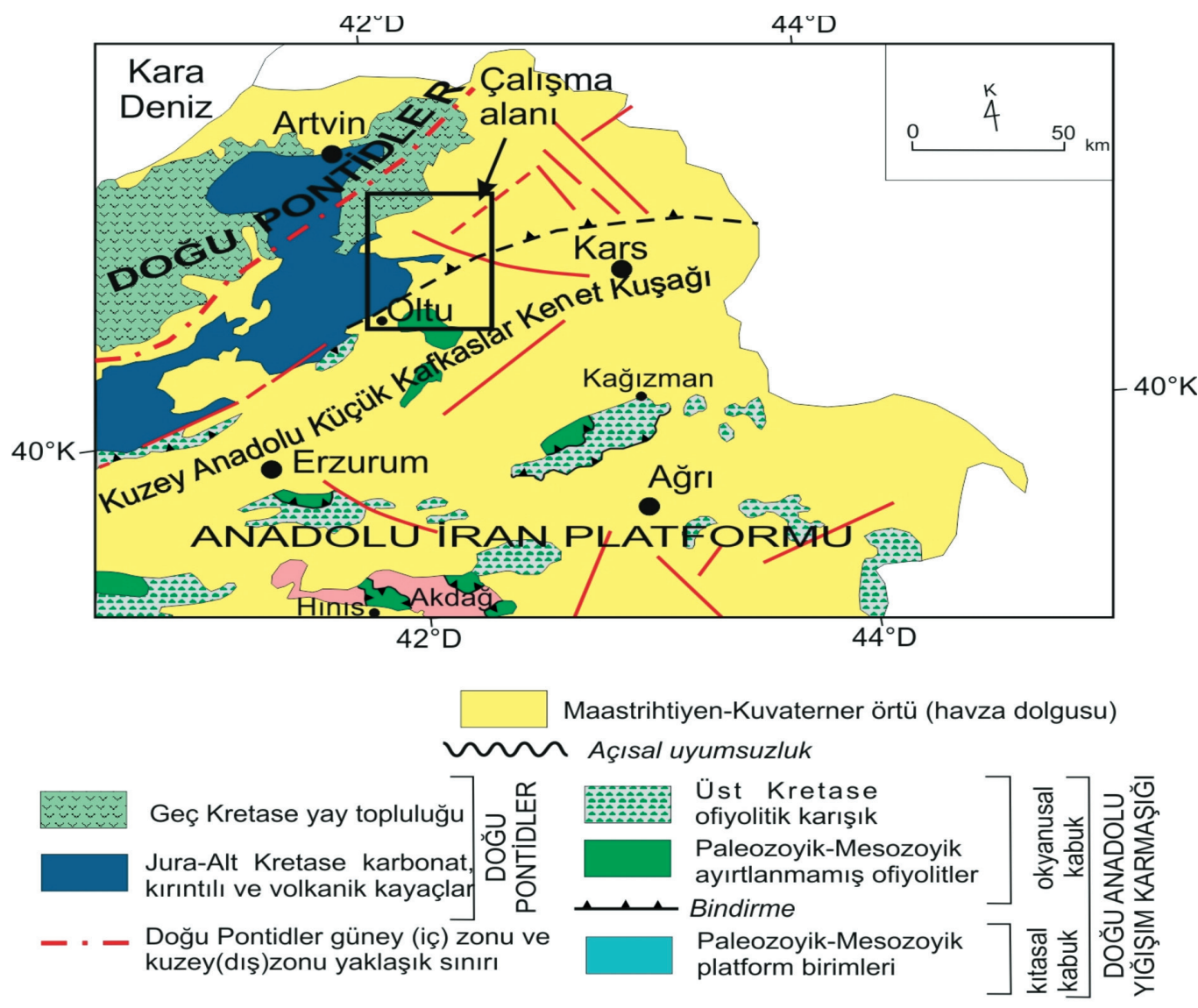

Şekil 1. Doğu Pontidler, Kuzey Anadolu-Küçük Kafkaslar Kenedi, Anadolu İran Platformu ve inceleme alanının konumu (Özsayar vd., 1981; Bektaş vd., 1995; Okay ve Şahintürk, 1997 ve Yılmaz vd., 2014〉den değiştirilerek).

Figure 1. Eastern Pontides, North Anatolian-Lesser Caucasus Suture Zone, Anatolian-Iranian Platform and location of study area. KAF, North Anatolian Fault; DAF, East Anatolian Fault (Modified from Özsayar et al., 1981; Bektaş et al., 1995; Okay and Şahintürk, 1997 and Yllmaz et al., 2014). 


\section{BÖLGESEL JEOLOJİ}

Oltu-Balkaya havzas1, güneyde Ankara-Erzincan Kenedi ve kuzeyde Doğu Pontidlerin yay önünü temsil eden zonun üzerinde gelişmiştir (Şekil 1). Doğu Pontidler, Geç Kretase-Tersiyer yaşta volkanik ve volkanokırıntılı kayaçların egemen olduğu kuzey (dış) zon ve Geç Kretase öncesi yaşlı yay önü tortul kayaçların yaygın olduğu güney (iç) zon olmak üzere ikiye ayrılmıştır (Akın, 1979; Gedikoğlu, 1979; Özsayar vd., 1981; Bektaş vd., 1995; Okay ve Şahintürk, 1997).

Doğu Pontid Kuzey Zonu esas olarak değişik yaş ve karakterde altı önemli magmatik etkinliğin ürünlerinden oluşmaktadır: 1. Yitimle ilişkili Turoniyen-Maastrihtiyen yaşta subalkalen volkanizma (Okay ve Şahintürk, 1997) ve Erken Kretase yaşlı ortaç K'lu erken yay kökenli granitoyid (Boztuğ vd., 2006), 2. Geç Kretase-Erken Paleosen yaşlı ortaç-yüksek K lu kalkalkalen olgunlaşmış yay kökenli granitoyid (Boztuğ vd., 2006), 3. Paleosen yaşlı peralumin lökogranit çarpışma ile çağdaş kökenli granitoyid (Şengör ve Y1lmaz, 1981; Y1lmaz vd., 1997; Okay ve Şahintürk, 1997; Boztuğ vd., 2004; Boztuğ vd., 2006), 4. Orta-Geç Eosen yaşlı çarpışma sonrası plütonizma ürünü, yüksek $\mathrm{K}$ 'lu kalkalkalen granitoyid (Genç ve Yılmaz, 1995; Yılmaz ve Boztuğ, 1996; Yılmaz vd., 1997; Topuz vd., 2005; Boztuğ vd., 2006), 5. Geç Eosen yaşl1, alkalen, ortaç kalkalkalen ve toleyitik karakterde genişleme ile ilişskili granitoyidler (Okay ve Şahintürk, 1997; Arslan ve Aslan, 2006; Boztuğ vd., 2006) ve 6. Orta Miyosen-Pliyosen yaşlı çarpışma sonrası volkanitler (Aydın vd., 2008; Eyüboğlu vd., 2012).

Doğu PontidGüney Zonu ise, DevoniyenKarbonifer yaşlı yüksek dereceli metamorfik kayaçlar, Alt Karbonifer yaşlı granitik ve dasitik kayaçlar, Üst Karbonifer-Alt Permiyen sığ denizel karasal kökenli bir molas ve Permo-Triyas yaşı bloklu metavolkano-tortul diziden oluşmaktadır
(Y1lmaz, 1972; Şengör ve Y1lmaz, 1981; Okay ve Şahintürk, 1997; Yılmaz vd., 1997; Topuz vd., 2004). Alt ve Orta Jura yaşlı kırıntılı tortul aratabakalı olasılıkla Neotetis'in kuzey kolunun açılmasını işaret eden riftleşme ile ilişsili tüf ve piroklastikleri ve Üst Jura-Alt Kretase karbonatları bu temelin üzerine açılı uyumsuzlukla gelmektedir (Görür vd., 1983). Güneye doğru volkanik ara katkıları giderek azalan ve yay-önü havza ürünü Senoniyen yaşlı olan bir çökel serisi, daha yaşlı birimleri aç1lı uyumsuzlukla örtmektedir (Pelin, 1977; Gürsoy, 1989; Fenerci, 1994; Robinson vd., 1995). Bu zonda Senoniyen sonrası yaşlı kuzeye dalımlı ve esas olarak ofiyolit ve ofiyolitli melanjlardan oluşan itki dilimleri gözlenmektedir.

$$
\text { Oltu-Balkaya havzasının güney }
$$

bölümünde daha yaygın olan Kuzey Anadolu Ofiyolit Kuşağı (Yılmaz vd, 2000) olarak tanımlanan ofiyolitik birimler, Pontidler ve Anadolu-İran Platformu arasinda bulunan Neotetis'in kuzey kolunun kapanması ile oluşan İzmir-Ankara-Erzincan Kenedinin (Şengör ve Yılmaz, 1981) doğu kesimini temsil ederler.

Doğu Pontidlerle daha doğudaki Kafkaslar arasındaki ilişkiler değişik çalışmalarla ortaya konulmaya çalışılmıştır. Örneğin Adamia vd. (1987) her iki bölgenin Paleozoyikteki tektonik gelişim ve Lordkipanidze vd.(1989) Mesozoyik-Senozoik dönemindeki magmatik evrim benzerliklerini araştırmışlardır. Yılmaz vd. (2000) ise Güney Transkafkasya ve Doğu Pontidlerin yapısal deneştirmesini yaparak Doğu Pontid Güney Zonunun yay önü topluluğu temsil eden İmbrike Bayburt Karabağ birimini ve kısmen Artvin Bolnisi magmatik yayın, Doğu Pontid Kuzey Zonunun ise k1smen Artvin Bolnisi magmatik yayını ve Adjara Trialeti birimininin tümünü kapsadığını ortaya koymuştur. Oltu Balkaya Havzası, bu birimlerden yay önü topluluğu temsil eden İmbrike Bayburt Karabağ 
birimi ve Kuzey Anadolu Ofiyolit Kuşağı üzerinde bulunmaktadır.

Pontidler ve Anadolu-İran Platformu'nun çarpışmaya başlamasından sonra İzmir-AnkaraErzincan Kenedi üzerinde Geç Kretase'den itibaren çok sayıda molas tipi havza gelişmiştir (Görür ve Tüysüz, 2001). Bu havzalardan Erzincan'ın batısındakiler ayrıntılı incelenmiştir (Örn. Refahiye, Sivas, Yıldizeli, Yozgat-Sorgun ve Çankırı havzaları, Görür vd., 1984; Kelling vd., 1989; Cater vd., 1991; Koçyiğit, 1996; Görür vd., 1998; Y1lmaz ve Y1lmaz, 2006). Ancak doğudaki havzaların evrimine yönelik olarak yeterince inceleme yapılmamıştır. Sunulan çalışma bu eksikliğin en azından bir bölümünü gidermeyi amaçlamaktadır.

\section{OLTU-BALKAYA HAVZASI}

Önceki çalışmalar ve kendi gözlemlerimiz birleştirilerek Oltu-Balkaya havzasını oluşturan temel ve dolgu birimleri Şekil 2 deki gibi haritalanmıştır. $\mathrm{Bu}$ birimlerin stratigrafik konumları, kaya türü özellikleri ve fosil içerikleri Şekil 3'teki genelleştirilmiş stratigrafik kolon kesitte sunulmuştur.

\section{Stratigrafi}

İmbrike Bayburt Karabağ birimini oluşturan yay önü topluluk ve Kuzey Anadolu Ofiyolit Kuşağının ofiyolitik birimlerinden oluşan bir temel üzerinde gelişmiş olan Oltu-Balkaya havzasının dolgu birimlerinin özellikleri aşağıdaki biçimde özetlenebilir.

\section{Atli formasyonu}

Birim ilk kez Yilmaz vd. (2000) tarafindan Atlılar formasyonu olarak adlandırılmıştır. Ancak adlandırmada kullanılan yerleşim alanının adı Atlı olduğu için bu çalışmada Atlı formasyonu alarak düzeltilmiştir. Oltu-Balkaya havzasının kuzeyinde Olur kuzeybatısında yüzeylenen yeşilimsi gri ve bej renklerin baskın olduğu birim, tabanda çapraz katmanlanmalı çakılttaşı ile başlamakta üste doğru karasal, çapraz katmanlanmalı kırıntılılar, ince tabakalı kireçtaşı, silttaşı ve kiltaşı aratabakalı kumtaş1, türbitik kireçtaşı, ince kalsitürbidit katmanlı yeşil kiltaşı ile devam etmekte, en üstte ise kiltaş1-silttaşı ardalanması ve karasal kırıntılı kayaçlarla sona ermektedir. Atlı formasyonu yaygın bir şekilde kıvrımlanmış ve ekaylanmış (Konak vd., 1995; Y1lmaz vd., 2000) Maastrihtiyen öncesi yaşlı yayönü çökel topluluğunu (Okay ve Leven, 1996) belirgin bir açısal uyumsuzlukla örtmektedir (Şekil 4A). Birimin üst kesimleri yanal olarak güneyde Oltu-Balkaya havzasında Paleosen yaşı ıahçelikışla formasyonuna (Konak vd., 2001) geçmektedir.

Fosil kapsamina (Globotruncana ventricosa White, Stomiosphera sphaerica (Kaufmann), Pithonella ovalis (Kaufmann), Calcisphaerula innominate Banet, Globotruncana gr linneiana (d'Orb.), Missisipina binehorsti (Reus), Epinoides sp., Planorbulina sp., Anomolina sp.) dayanılarak MaastrihtiyenPaleosen yaşlı olarak kabul edilen birim (Yılmaz vd.(2000) başlangıçta karasal daha sonra sı̆̆ denizel bir ortamı yansitmaktadır. 


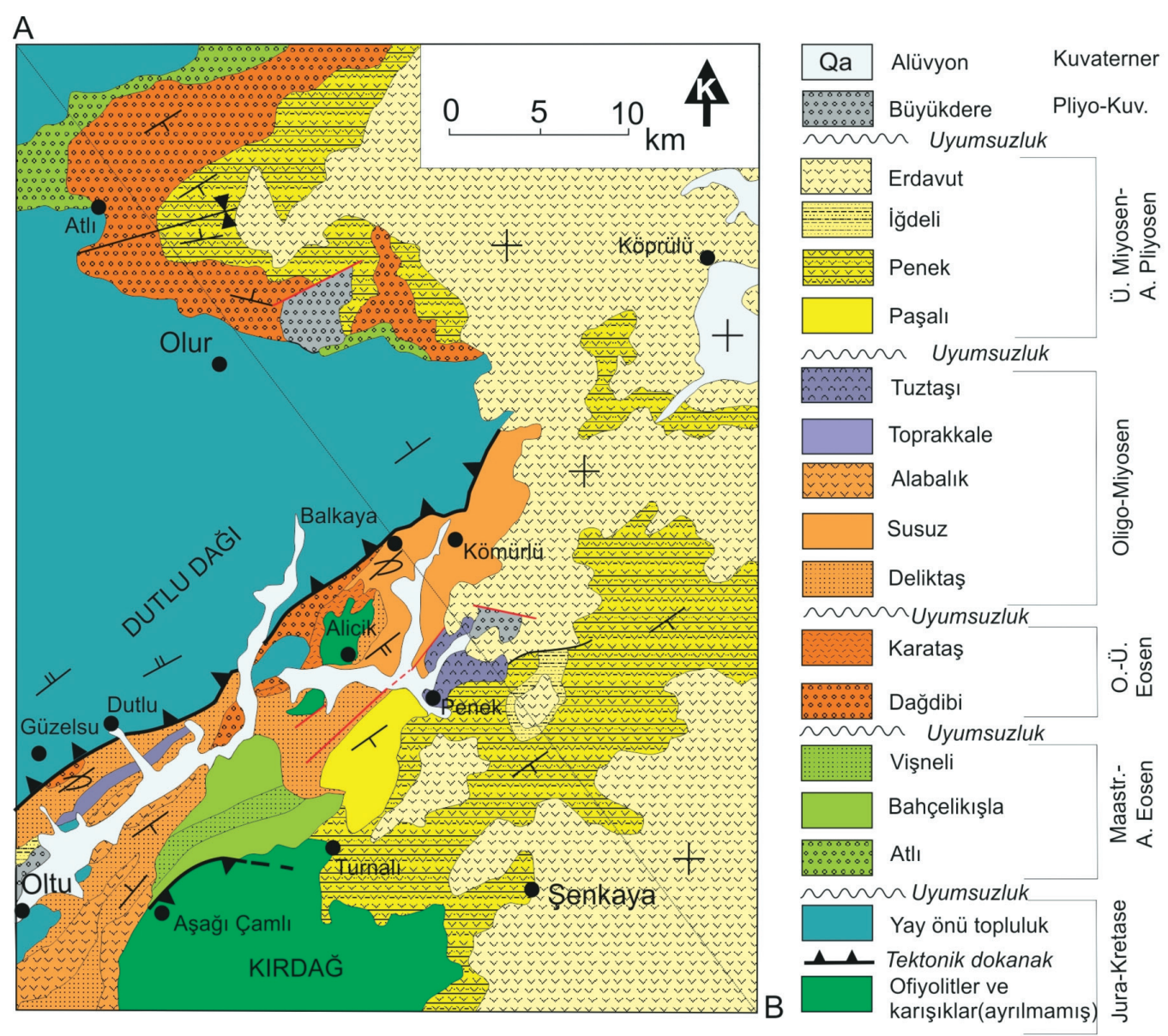

\section{SEMBOLLER}
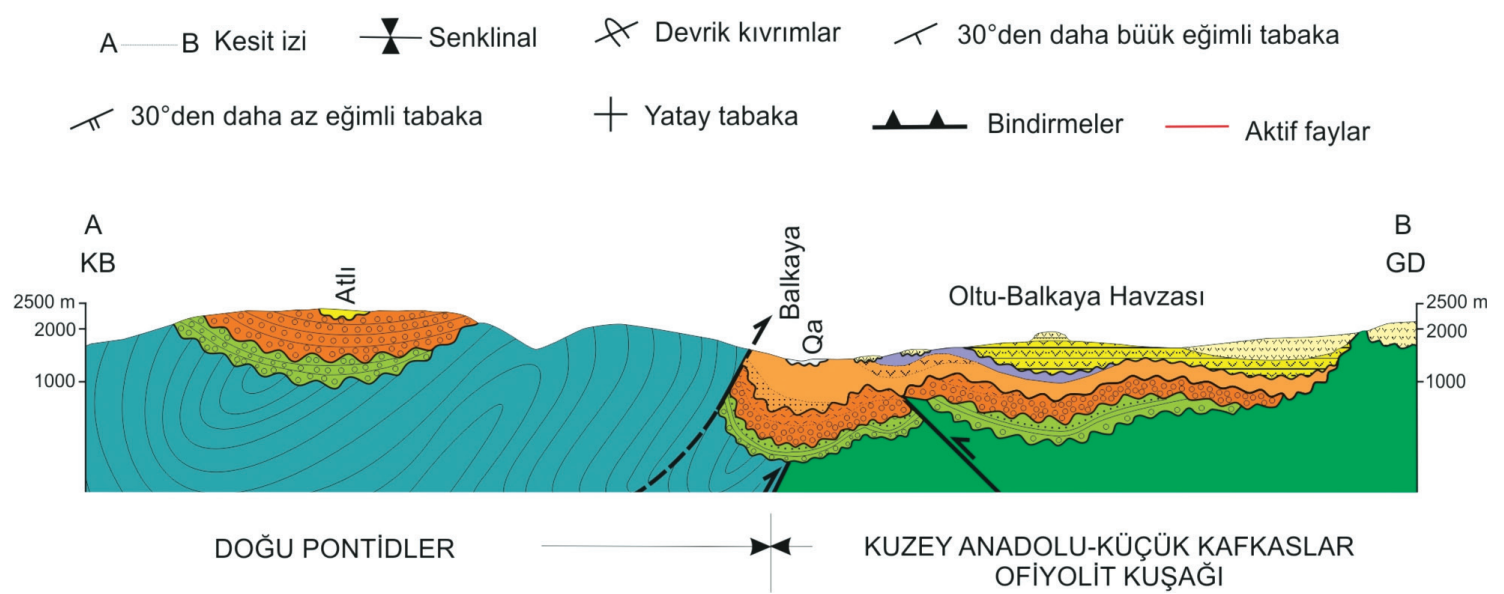

Şekil 2. Oltu-Balkaya havzasının haritası ve enine jeoloji kesiti (Özdemir, 1981; Konak vd., 2001; MTA, 2002 ve Yılmaz vd., 2003 ve yeni gözlemler. Yer bulduru için Şekil 1>e bkz.).

Figure 2. Geological map and cross-section of the Oltu-Balkaya Basin (After Özdemir, 1981; Konak et. al., 2001; MTA, 2002 and Yllmaz et. al. 2003 and new revision. See Figure 1 for locations). 


\section{Bahçelikışla formasyonu}

Konak vd. (2001) tarafindan tanımlanan ve genel olarak bordo-yeşil-gri renkli, yer yer belirsizleşen kalın katmanlı çakıltaşı-kumtaşı ardalanımıyla temsil edilen birimdeki gereçler volkanit, serpantinit, glokofanlı yeşil şist ve kireçtaşları gibi yayönü topluluklarda bol oranda bulunan kayaçlardan türemiştir. Kumtaşları kalın-orta katmanl1, yer yer büyük ve küçük ölçekli çapraz katmanlı ve bitki kırıntılı olup, gri renkli, ince silttaşı ara katmanları içerir. Birimin üst kısmını, çakıllı kumtaş1-kumtaşı ve beyaz kireçtaşı ara katmanları içeren, kalın düzeyler halindeki kırmızı-kahverengi çamurtaşları oluşturur.
Bahçelikışla formasyonu, Oltu kuzeyinde bazı yerlerde ofiyolitli karışığın üzerine uyumsuzlukla gelirken (Şekil 4B) bazı yerlerde ise ofiyolitli karışık tarafından tektonik dokanakla üzerlenilir (Şekil 4C). Birim Oltu güneyinde bazı yerlerde Vişneli formasyonuna (Konak vd. 2001) uyumlu olarak geçiş yapar.

Birim içinde herhagi bir fosil saptanamamasına karşıı üzerinde geçişli olarak yer alan Vişneli formasyonunun Erken Eosen yaşında olması nedeniyle Bahçelikışla formasyonunun yaşı Geç Paleosen (?)-Erken Eosen olarak kabul edilmiştir (Konak vd.2001).

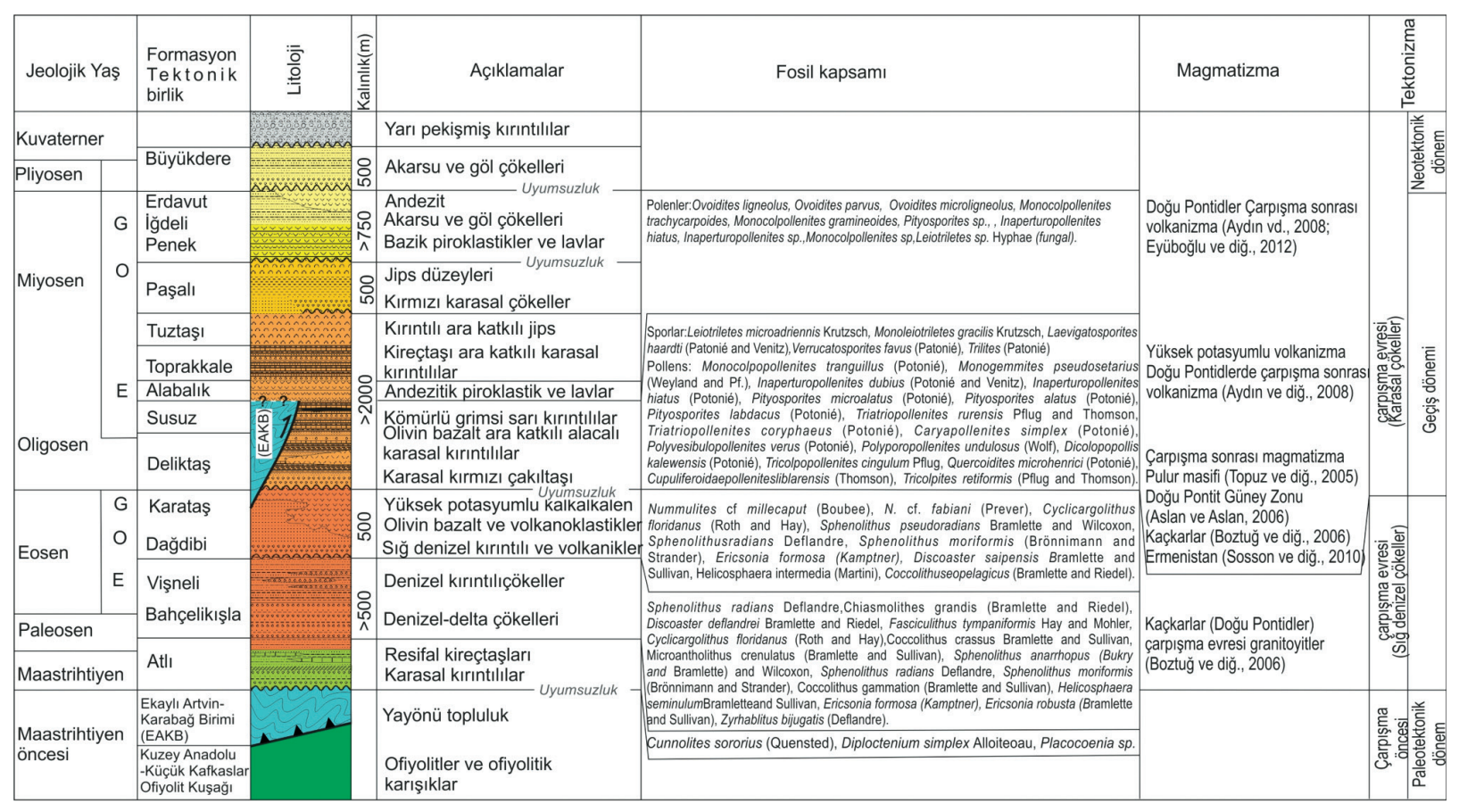

Şekil 3. Oltu-Balkaya havzasındaki birimlerin, stratigrafik konumları, kayatürü özellikleri, havza çevresindeki magmatik veriler, tektonik dönemler ve evrim aşamaları (Özdemir, 1981; Bozkuş, 1990; Bilgiç vd., 1995 Konak vd. 2001, Yılmaz vd., 2003 Topuz vd., 2005; Aslan ve Aslan, 2006; Boztuğ vd., 2006; Aydın vd., 2008; Sosson vd., 2010; Eyüboğlu vd., 2012 ve yeni gözlemler).

Figure 3 Stratigraphic positions and lithological characteristics of the units in Oltu-Balkaya Basin and magmatic data, tectonic periods and structural stages of its surrounding area (After Özdemir, 1981; Bozkuş, 1990; Bilgiç et al., 1995 Konak et. al. 2001, Yllmaz et. al., 2003 Topuz vd., 2005; Aslan and Aslan, 2006; Boztuğ et al., 2006; Aydın et al., 2008; Sosson vd., 2010; Eyüboğlu et al., 2012 and new revision). 
Birimde birkaç kez yinelenen biçimde devresel olarak, altta ince taneli kırıntılı kayaçlarla başlayıp üste doğru iri çakıltaşlarına geçişler, büyük ölçekli çapraz katmanlanmalar ve yer yer dalga etkisiyle yeniden işlenmiş yassı çakıllar içeren çakıltaşı düzeyleri denizel ve delta ortamını düşündürmektedir.

\section{Vişneli formasyonu}

İlk kez Konak vd. (2001) tarafindan Vişneli formasyonu olarak tanımlanan ve esas olarak griyeşil renkli, orta katmanlı, altta kumtaşı, üstte ise kumtaşı-silttaşı ardalanımı ile temsil edilen birimin tabanında yer yer kötü boylanmalı çakıltaşı mercekleri içeren orta ve kalın katmanlı sarımsı gri-yeşil renkli kumtaşları, üst kesimlerinde ise yer yer çakıltaşı düzeyleri içeren, ince-orta katmanlı sarımsı gri türbiditik kumtaşı ve gri-yeşil silttaşı ardalanması gözlenmektedir. Bu birimdeki gereçler de volkanit, serpantinit, glokofanlı yeşil şist ve kireçtaşları gibi yayönü topluluklarda bol bulunan kayaçlardan türemiştir. Birimde keskin katman tabanları, taban yapıları, derecelenme, paralel laminalanma, bitki kırıntıları ve canlı eşeleme izleri gözlenmektedir (Bozkuş, 1993).

Bahçelikışla formasyonunun üzerinde uyumlu ve geçişli olarak yer alan Vişneli formasyonu Dağdibi formasyonu tarafindan yerel bir uyumsuzlukla örtülmektedir (Bozkuş, 1993),

Oltu çevresinde Konak vd.(2001) tarafından derlenen örneklerde saptanan fosil içeriğine göre [(Sphenolithus radians Deflandre, Chiasmolithus grandis (Bramlette ve Riedel), Discoaster deflandrei Bramlette ve Riedel, Discoaster kuepperi (Stradner), Coccolithus eopelagicus(Bramlette ve Riedel), Fasciculithus tympaniformis Hay ve Mohler, Coccolithus crassus Bramlette ve Sullivan, Coccolithus formosus (Kamptner), Cyclolithella robusta (Bramlette ve Sullivan), Micrantholithus crenulatus (Bramlette ve Sullivan), Sphenolithus moriformis (Brönnimann ve Stradner), Sphenolithus anarrhopus (Bukry ve Bramlette), Coccolithus gammation (Bramlette ve Sullivan), Zygrhablithus bijugatus (Deflandre)) (Sphenolithus moriformis (Brönnimann ve Stradner), Sphenolithus radians Deflandre, Helicosphaera seminulum Bramlette ve Sullıvan, Coccolithus eopelagicus (Bramlette ve Riedel), Ericsonia formosa (Kamptner), Ericsonia robusta (Bramlette ve Sullivan), Ericsonia ovalis Black, Zygrhablithus bijugatus (Deflandre), Toweius tovae Perch-Nielsen, Discoaster sp.)] birimin Erken Eosen yaşta olduğu belirlenmiştir. $\mathrm{Bu}$ fosil içeriği ve yukarıda tanıtılan türbiditik özelliği gözönüne alındığında birimin giderek derinleşen denizel bir ortamda çökeldiği ileri sürülebilir.

\section{Dağdibi formasyonu}

Bozkuş (1993) tarafından adlandırılan formasyon, tabanda gri-yeşil renkli, masif ve yer yer kalın katmanlı, çok tür bileşenleri az yuvarlaklaşmış, kötü boylanmalı, yer yer kumtaşı mercekleri içeren bir taban konglomerasıyla başlamakta ve üste doğru gri, açık gri ve grimsi mavi renkli, masif, bol fosilli ince taneli kumtaşı ve silttaşı ile devam etmektedir.

Vişneli formasyonu üzerinde yerel bir uymsuzlukla yer alan Dağdibi formasyonu üstte Karataş formasyonuna uyumlu olarak geçmektedir Birim içerisinde Nicaeotrochus cyclolitoides (Bellard1), Nummulites aquiatanicus (B formlar1), Nummulites cf. uroniensis de la Harpe (A ve B formlar1), Nummulites sp., Discocyclina sp., Operculina sp. gibi fosiller saptanmış ve Dağdibi formasyonuna Alt-Orta Eosen (Küviziyen-Alt Lütesiyen) yaşı verilmiştir (Bozkuş, 1993). 

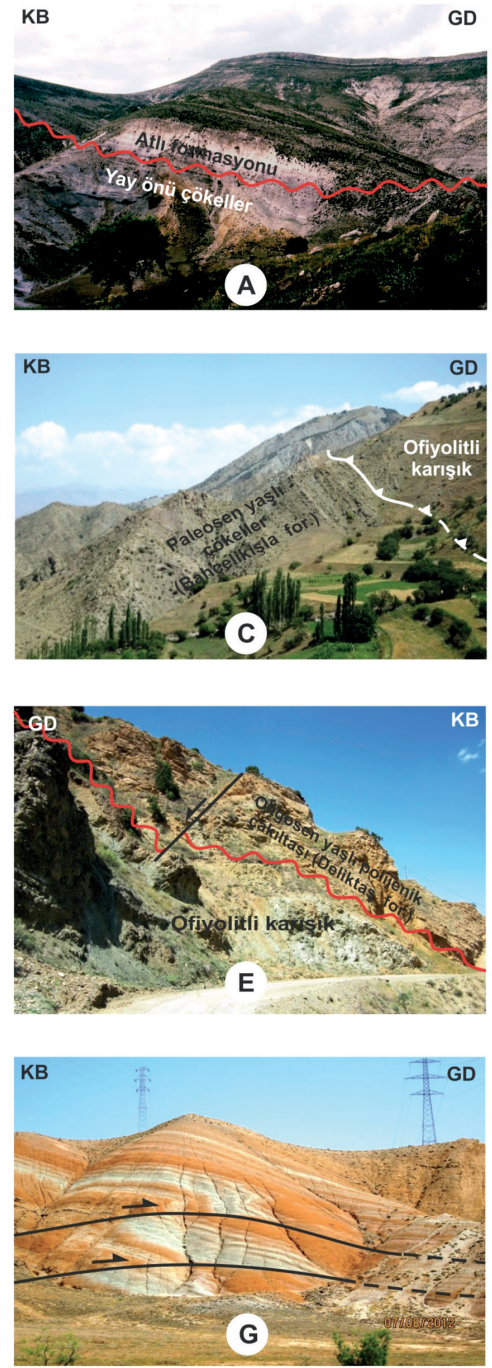
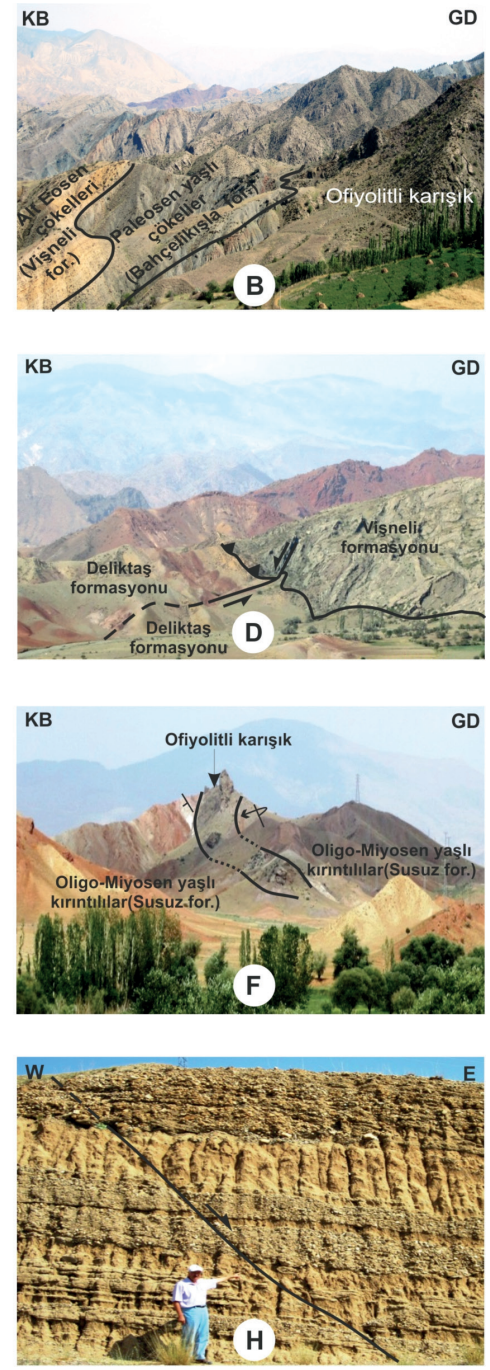

Şekil 4. Oltu-Balkaya havzasıyla ilişkili değişik arazi görüntüleri: A-Oltu-Balkaya havzasının kuzeyinde Olur kuzeybatısındaAtlıl formasyonu veyayönütopluluk arasındaki açısal uyumsuzluk. B-Oltukuzeydoğusunda Bahçelikışla formasyonu ve ofiyolitli karışık arasındaki uyumsuzluk. C-Oltu kuzeydoğusunda ofiyolitli karışık ve Bahçelikışla formasyonu arasındaki tektonik dokanak. D-Oltu kuzeydoğusunda Deliktaş formasyonu ve Vişneli formasyonu arasındaki uyumsuzluk ve tektonik dokanak. E-Ofiyolitli karışık üzerindeki Oligosen yaşta polijenik konglomera. F-Oligo-Miyosen yaşta birimlerde KD-GB eksen gidişli, yer yer güneye devrik kıvrımlar ve çekirdekteki ofiyolitli karışık. G-Tuztaşı formasyonundaki bindirmeler ve bindiren bloklar üzerinde gelişmiş küçük kıvrımlar. H-İğdeli formasyonundaki KB-GD doğrultulu KD ve GB ya eğimli doğrultu atım bileşenli normal faylar.

Figure 4. Varied field views from the Oltu-Balkaya Basin. A-Angular unconformity between Atllar formation and fore-arc association northwest of Olur in the north of the Oltu-Balkaya Basin. B-Angular unconformity between Bahçelikuşla formation and ophiolitic melange in the northeast of Oltu. C- Tectonic contact between Bahçelikşla formation and the ophiolitic melange in the northeast of Oltu. D-Unconformity and tectonic contact between Deliktas formation and Vişneli formation in the northeast of Oltu. E-Oligocene polygenic conglomerate on the ophiolitic melange. F- From place to place northward overturned folds with NE-SW axial extending in Oligo-Miocene units and the ophiolitic melange in their core. $G$ - Overthrusts and small folds developed on the overthrust block in Tuztaşl formation. H-The NE-SW striking and $N E$ and $S W$ dipping normal faults with strike-slip component in İgdeli formation. 
Konak vd. (2001) ise Dağdibi formasyonuna, taban çakıltaşının hemen üzerine gelen kumtaşlarından derlenen örneklerde saptanan Nummulites cf. millecaput Boubee (A formu), Nummulites cf. fabianii Prever, Nummulites spp., Discocyclina spp., Assilina sp., Asterigerina sp., Eurupertia sp., Acticocyclina sp., Rotalia sp.) ve nannoplankton faunasina (Cyclicargolithus floridanus (Roth ve Hay), Sphenolithus pseudoradians Bramlette ve Wilcoxon, Sphenolithus radians Deflandre, Sphenolithus moriformis (Brönnimann ve Stradner), Ericsonia formosa (Kamptner), Ericsonia ovalis Black, Coccolithus eopelagicus (Bramlette ve Riedel), Helicosphaera lophota Bramlette ve Sullivan, Reticulofenestra umbilica (Levin), Cribrocentrum coenurum (Reinhardt), Discoaster saipanensis Bramlette ve Riedel, Discoaster deflandrei Bramlette ve Riedel, Discoaster elegans Bramlette ve Sullivan, Braarudosphaera bigelowi (Gran ve Braarud), Micrantholithus crenulatus (Bramlette ve Sullivan), Pontosphaera plana (Bramlette ve Sullivan), Rhabdosphaera inflata (Bramlette ve Sullivan), Helicosphaera intermedia (Martini), Transversopontis pulcher (Deflandre), Transversopontis pulcheroides (Sullivan), Calcidiscus kingii (Roth), Chiasmolithus sp. fosil içeriği Bartoniyen-Erken Priyaboniyen (OrtaGeç Eosen) yaşını vermektedir. Bu çalışmada da fosil kapsamının daha ayrıntılı saptanılmasına dayanılarak aynı yaş benimsenmiştir.

Birim yüksek enerjili, sı ̆̆ denizel bir ortam ürünüdür.

\section{Karataş formasyonu}

Bozkuş (1990) tarafından adlandırılan birim tabanda, gri-yeşilimsi gri renkli, ince orta tabakalı kumtaşları ve üstte silttaşı, kiltaşı, siyah renkli bazalt, tüf ve kumtaşı ardalanmasından oluşmaktadır. Birimin, yer yer merceksi geometrili, kalın gri-yeşil renkli aglomera ara düzeyleri, litik ve kristal tüf karakterine sahip olan porfirik dokulu tüfler ve olivin bazaltlardan oluşan volkanik kesimi yüksek potasyumlu kalkalkalen bir volkanizmanın ürünüdür (Konak vd., 2001) ve bunların arasında bulunan gastropodlu kireçtaşları ve ince taneli kırıntılı kayaçlar gölsel ortamı temsil etmektedir (Konak ve Hakyemez, 2008).

Dağdibi formasyonu üzerinde uyumlu olarak bulunan Karataş formasyonu açılı uyumsuzlukla Deliktaş formasyonu tarafından örtülmektedir.

Volkanik kumtaşı ve tüflerle ardalanan silttaşlarında saptanan Reticulofenestra umbilica (Levin), Cribrocentrum coenurum (Rheinhardt), Cyclicargolithus floridanus (Roth ve Hay) ve Ericsonia formosa (Kamptner) nannoplankton türlerine dayanılarak birime BartoniyenPriyaboniyen (Orta-Geç Eosen) yaşı verilmiştir (Konak ve Hakyemez, 2008).

Birim tabanda denizel üste doğru gölsel ortam özelliği sunmaktadır.

\section{Deliktaş formasyonu}

Bozkuş (1990) tarafından adlandırılan birim, tabanda kırmızı, mor, kahverengi renkli merceksel, binik yapılı çakıltaşı, çakıllı kumtaşı ara katkı11, masif, yer yer çok kalın katmanlı kumtaşı, çamurtaş1, silttaşı, tüf ve kireçtaş1 ardışımından oluşmaktadır. Birimde yer yer aglomera ve bazalt ara katkıları da gözlenmektedir.

$\mathrm{Bu}$ formasyon Oltu kuzeydoğusunda Vişneli formasyonunun üzerine açısal uyumsuzlukla gelmekte ve aynı lokasyonda aynı birim tarafından tektonik olarak üzerlenilmektedir (Şekil 4D). Deliktaş formasyonunun ofiyolitli karışıkla ilişkisi, önceki çalışmalarda (örn. Konak ve Hakyemez, 2008) Oltu doğusunda Aşağ1 Çamlı yakınlarında tektonik olarak tanıtılmıştır. Ancak arazi çalışmaları sırasında aynı yerde 
Deliktaş formasyonunun tabanda polijenik bir taban konglomerasıyla ofiyolitli karışı̆̆ açısal uyumsuzlukla üzerlediği de gözlenmektedir (Şekil 4E).

Benda (1971)'nın kömürlerde yaptığ1 palinolojik çalışmalara göre (Kurbalık sporomorph association) birimin yaşı Geç Oligosen-Erken Miyosendir.

Birimin litolojik ozellikleri, aşındırma tabanlı kanal dolguları, som katmanlanma, kötü boylanmalı çakıllı kumtaşları ve merceksel kömür ara katkıları (Bozkuş, 1990), fosil kapsamı (Melanopsis sp. (Konak vd., 2001) ve kömur içermesi sı̆̆ göl, bataklık, akarsu ve alüvyon yelpazesi ve göl ortamlarındaki depolanmayı belirtmektedir.

\section{Susuz Formasyonu}

Bozkuş (1990) tarafından adlandırılan formasyon yer yer kömür damarları içeren, yeşil-sarı-kırmızı renkli çakıltaş1-kumtaş1-çamurtaş1-kireçtaş1 ardalanmasından oluşmuştur

Deliktaş formasyonu üzerinde uyumlu olarak yer alan birim üste doğru Alabalık formasyonuna uyumlu olarak geçmektedir.

Birimin palinolojik içeriği [Sporlar: Laevigatosporites haardtii (Potonié ve Venitz), Leiotriletes microadriennis Krutzsch, Verrucatosporitesfavus(Potonié), Monoleiotriletes gracilis Krutzsch, Trilites solidus (Potonié), Polypodiceoisporites marxheimensis (Murr ve Pflug), Leiotriletes adriensi, Verrucatosporites alienu, Cingulatisporites macrospecious, Echinatisporis sp., Laevigatosporites sp. Echinatosporites sp., Leiotriletes sp. Pollenler: Monogemmites pseudosetarius (Weyland ve Pflug), Inaperturopollenites dubius (Potonié ve Venitz), Pityosporites microalatus (Potonié), Monocolpopollenites tranguillus (Potonié),
Monogemmitespseudosetarius(Weyland vePflug), Triatriopollenites rurensis Pflug ve Thomson, Tricolpites retiformis (Pflug ve Thomson), Dicolpopollis kalewensis (Potonié), Quercoidites microhenrici (Potonié), Cyrillaceaepollenites megaexactus (Potonié), Periporopollenites stigmosus, Monoporopollenites solaris, Triatriopollenites coryphaeus, Anatolinites dongingensis, Cupressacites sp.] Geç OligosenErken Miyosen yaşını vermektedir (Bilgiç vd., 1995; Konak vd., 2001).

Birim karasal ortam ürünüdür.

\begin{abstract}
Alabalık formasyonu
Konak ve Hakyemez (2008) tarafindan adlandırılan birim sarı-yeşil renkli tüf, aglomera ve andezitik lavlardan oluşmuştur. Alabalık formasyonu altındaki Susuz formasyonu ve üstündeki Toprakkale formasyonu ile uyumlu geçişlidir. Birimin $\mathrm{Rb} / \mathrm{Sr}$ ve K/Ar yöntemleriyle yaşı 23 MY (Erken Miyosen) olarak belirlenmiştir (Bayraktutan 1994).
\end{abstract}

\section{Toprakkale formasyonu}

Bozkuş (1998) tarafindan tanıtılan birim, koyu gri, gri, yeşil, açık kahverengi, sarımsı bej renkli çakıltaş1, kumtaşı, çamurtaş1, kiltaş1 ardışımlı bir istiften oluşmakta ve yer yer kireçtaşı katmanları içermektedir. Toprakkale formasyonu altındaki Alabalık formasyonu ve üstündeki Tuztaşı formasyonu ile uyumlu geçişlidir. Stratigrafik konumu gereği Erken Miyosen ya da daha genç yaştaki birim karasal ve gölsel ortam ürünü olmalıdir.

\section{Tuztaşı formasyonu}

Bozkuş (1998) tarafindan adlandırılan birim, alttan üste doğru kırmızı renkli çakıltaşı-kumtaş1çamurtaşı ardalanması, sarı-gri-açık kırmızı renkli kireçtaşı-kumtaşı-çamurtaşı ardalanımı ve 
sarı-kırmızı renkli ve kalın katmanlı çakıltaşıçamurtaş1-kumtaş1 ardalanmasından oluşmuştur. Tuztaşı formasyonu, altındaki Toprakkale formasyonu ile uyumlu geçişlidir. Birim Paşalı formasyonu tarafindan yerel uyumsuzlukla örtülür. Stratigrafik konumu gereği Geç OligosenErken Miyosen yaşta kabul edilen birim, karasal ve playa gölü ortamını yansıtmaktadır (Konak vd., 2001).

\section{Paşalı formasyonu}

Konak vd. (2001) tarafindan adlandirılan birim, sar1-kırmızı renkli çakıltaşı-kumtaş1-çamurtaş1 ardalanımından oluşmakta ve taban kesiminde kireçtaşı ara katkıları içermektedir.

\section{Paşalı formasyonu, Toprakkale} formasyonu üzerinde uyumlu ve geçişli olarak yer almaktadır. Birimin üzerinde ise, Penek formasyonu açılı uyumsuzlukla bulunmaktadır. Stratigrafik konumu göz önünde bulundurularak birimin yaşı Geç Oligosen(?)-Erken Miyosen kabul edilmiştir (Konak ve Hakyemez, 2008).

Paşalı formasyonu içindeki çakııltaşları yer yer blok boyutunda, heterojen, yuvarlaklaşmış çakıllardan oluşmuş, taban dokanakları keskin yanal olarak devamsız düzeyler halindedir. Kumtaşlarında çapraz tabakalanmalar gözlenmektedir. Birimin kaya türü özellikleri göl ve akarsu ortamını yansitır niteliktedir.

\section{Penek formasyonu}

Bozkuş (1990) tarafından tanımlanan birim, siyah, koyu gri, sarımsı-kahverengi, katmansız, yer yer çok kalın katmanlı, andezit ve bazalt bileşenli, ince ve merceksel tüf, bazaltik ve andezitik lav ve aglomeralardan oluşmaktadır. Aglomeraların arasında bej renkli ince taneli kırıntılı mercekler bulunmaktadır. Penek formasyonu, Paşalı formasyonu üzerinde açısal uyumsuzlukla yer alır ve üste doğru İğdeli formasyonuna uyumlu olarak geçer. Konak vd.'ne (2001) göre birimin değişik düzeylerinin radyometrik yaş1 $10.6 \pm 2.8$ ve $6.7 \pm$ 1.29 MY (Geç Miyosen) arasında değişmektedir.

\section{İğdeli formasyonu}

Bozkuş (1990) tarafindan tanımlanan birim, sarı-bej renkli volkanik kökenli çakıltaşı, çapraz katmanlanmalı kumtaşı, gri-koyu gri tüf ve bazaltik lav arakatkılı, yer yer laminalı çamurtaşı, kiltaşı ve kömür aradüzeylerinden oluşmaktadır. İğdeli formasyonu altındaki Penek formasyonu ve üstündeki Erdavut volkaniti ile uyumlu geçişlidir. Birim içindeki volkanik kayaç arakatkılarındanı Konak vd. (2001) 6.7 \pm 1.29 MY. (Geç Miyosen) radyometrik yaş elde etmişlerdir. Kaya türü özellikleri birimin çökelmeye zaman zaman volkanizmanın eşlik ettiği gölsel ortamı yansıtır özelliktedir.

\section{Erdavut volkaniti}

Konak vd. (2001) tarafından adlandırılan birim genelde gri, mor, kahve, yeşilimsi siyah renkli bazaltik kayaçlar, andezitik-dasitik lav ve piroklastiklerden oluşmuştur. Erdavut volkaniti İğdeli formasyonu üzerinde geçişli olarak bulunur ve Büyükdere formasyonu tarafindan açısal uymsuzlukla örtülür. Konak vd. (2001) birimin üst seviyelerinden $6.3 \pm 1 \mathrm{MY}$ (Geç Miyosen) radyometrik yaş elde etmişlerdir.

\section{Kuvaterner birimleri}

\section{Büyükdere formasyonu}

Konak vd. (2001) tarafindan adlandırılan birim genelde sarımsı kahverengi gri renkli, yarı pekişmiş, katmansız çakıltaşlarından oluşmakta ve yer yer kumtaşı ve çamurtaşı arakatkıları içermektedir. Büyükdere Formasyonu, Erdavut volkaniti ve daha yaşlı birimleriin üzerinde 
açısal uyumsuzlukla yer almakta ve alüvyonal çökeller tarafından uyumsuz olarak örtülmektedir. Herhangi bir fosil içermeyen birim stratigrafik konumu gözetilerek Pliyo-Kuvaterner yaşlı olarak kabul edilmiştir. Birim akarsu ortamı ürünüdür.

\section{Alüvyon \\ Değişen türdeki köşeli, yarı köşeli, az veya iyi yuvarlaklaşmış, tutturulmamış blok, çakıl, kum, silt ve çamurdan oluşmaktadır.}

\section{Yamaç molozu}

Dağ ve tepelerin eteklerinde çökelmiş, iyi tutturulmamış, köşeli, tane destekli çakıl ve bloklardan oluşmaktadır.

\section{OLTU-BALKAYA HAVZASININ TEKTONIK EVRİMI VE MAGMATIZMASI}

Havza dolgusunun iç yapısı, temel ve örtü kayaçları arasındaki ilişkiye dayalı olarak OltuBalkaya havzasının beş aşamalı bir evrim geçirdiği ileri sürülebilir.

\section{Maastrihtiyen öncesi dönem}

Oltu ve çevresinde Maastrihtiyen öncesi temel, Liyas öncesi yaşlı metamorfik kayaçlardan oluşan yoğun kıvrımlanmış yay önü topluluk, yay volkanitleri, Neotetis kuzey koluna ait ofiyolit ve ofiyolitli karışıkları kapsayan KD-GB doğrultulu KB ve GD ya bakan ekay dilimlerinden oluşmaktadır. Maastrihtiyen öncesinde KB-GD doğrultulu bir sıkışma rejimini yansıtan bu kıvrımlı ve ekaylı yapılar belirgin bir açısal uyumsuzlukla Geç Maastrihtiyen-Paleosen yaşlı türbiditik karasal kırıntılılar ve resifal kireçtaşı ardalanması (Atl1 formasyonu) tarafindan örtülmektedir (Y1lmaz vd., 2000).

\section{Maastrihtiyen-Erken Eosen dönemi}

Oltu-Balkaya havzas1, Doğu Pontid Yay1 ve Neotetis Okyanusunun kuzey kolunun kapanmasıyla ilişkili ofiyolit kenedine ait Maastrihtiyen öncesi yaşlı tektonik birimler üzerinde Maastrihtiyen başlarında Pontidlerle Anadolu-İran Platformu'nun çarpışmasını izleyen yerel tektonik çökme ile oluşmaya başlamıştır. Başlangıçta havzada, volkanit, serpantinit, glokofanlı yeşil şist ve kireçtaşları gibi yayönü topluluklarda bol bulunan kayalardan türemiş kırıntılar içeren çapraz katmanlanmalı konglomera ile başlayan ve üste doğru daha ince kırıntılılara geçen karasal bir istif çökelmiştir. Paleosen'de derinleşen havzada kireçtaşlarıyla ardalanan kalın çamurtaşları çökelmiş ve Erken Eosende delta-deniz ortamı çökelleri gelişmiştir. Bölgede Maastrihtiyen-Erken Eosen yaşlı formasyonların Maastrihtiyen öncesi temel ile dokanakları yer yer stratigrafik ve yer yer de tektoniktir. Yay önü topluluk ve ofiyolitik birimler, KD-GB doğrultulu $\mathrm{KB}$ ve GD ya bakan bindirme fayları boyunca Maastrihtiyen-Erken Eosen yaşta birimlerin üzerine itilmiştir. $\mathrm{Bu}$ birimlerde $\mathrm{KD}-\mathrm{GB}$ eksen gidişli kıvrımlar gözlenmektedir. $\mathrm{Bu}$ durum KB - GD doğrultulu bir sıkışma rejimininin bu dönemde de sürdüğüne ve havzanın bu rejimin denetiminde geliştiğine kanıt sayılabilir. OltuBalkaya havzasinın kuzeyinde Pontidlerde Kaçkar Dağlarında Paleosen yaşta peralumin lökogranit özellikli çarpışma ile çağdaş kökenli granitoyidik bir magmatizma gelişmiştir (Boztuğ vd., 2006). Bu özellikleriyle çarpışma ile çağdaş önülke havzası olan Oltu-Balkaya havzasının doğusunda, aynı dönemde Küçük Kafkaslarda Anadolu-İran Platformu'nun doğudaki uzantısı Güney Ermenistan ile Pontidlerin doğudaki uzantısı Somkheto-Karabakh'ın arasında da syncollisional önülke niteliğinde bir havza gelişmiştir (Sosson vd., 2010). 


\section{Orta-Geç Eosen Dönemi}

$\mathrm{Bu}$ dönemde bölgede yükselmeyi kanıtlayan bir taban konglomerasıyla başlayan sı̆̆ denizel karakterli istif (Dağdibi formasyonu) çökelimine yüksek potasyumlu kalkalkalen bir volkanizma (Karataş formasyonu) da eşlik etmiştir (Konak vd., 2001). Doğu Pontidlerde bu volkanizmayla eş yaşlı magmatik aktivite için bazı araştırmacılar yay kökeni ileri sürerken (Tokel, 1977; Akın, 1979; Y1lmaz, 1981; Ercan ve Gedik, 1983; Robinson vd., 1995) bazıları çarpışma sonrası genişlemeli bir tektonik rejimi önermektedirler (Şengör ve Yılmaz, 1981; Genç ve Yılmaz, 1995; Y1lmaz ve Boztuğ, 1996; Yılmaz vd., 1997; Okay ve Şahintürk, 1997; Boztuğ vd., 2003, 2004). Son yıllarda yapılan çalışmalarda, Pulur Masifinin kuzeyinde Geç Paleosen-Erken Eosen yaşlı çarpışma ürünü nap yığınını kesen 52 MY (İpresiyen) yaşta (Topuz vd., 2005), Doğu Pontid Güney Zonunda 44 MY (Lütesiyen) yaşta (Arslan ve Aslan, 2006) ve Kaçkar Dağlarında OrtaGeç Eosen yaşta çarpışma sonrası yüksek K'lu kalkalkalen magmatizma ürünleri belgelenmiştir (Boztuğ vd., 2006). İnceleme alanının doğusunda Sosson vd. (2010) Güney Ermenistan- SomkhetoKarabakh bölgesinde Eosen magmatik etkinliğinin çarpışma sonrası oluştuğunu açıklamışlardır.

Geç Eosen sonuna doğru Maastrihtiyen öncesi yaşlı temel kayaçlar, KD-GB doğrultulu $\mathrm{KB}$ ve GD ya bakan bindirme fayları boyunca Maastrihtiyen-Erken Eosen yaşlı birimlerin üzerine itilmiş ve havza KB - GD yönlü sıkışma rejiminin etkisiyle yükselmiştir.

\section{Oligosen-Erken/Orta Miyosen Dönemi}

Oligosen'de gelişen bölgesel bir transgresyon sonrasinda havzada, Oligosen-Erken/Orta Miyosen aralığında karasal kırıntılılarla birlikte sığ denizel karbonatlar da içeren bir molas çökelmiştir. Maastrihtiyen öncesi yaşlı temel kaya birimleri, KD-GB doğrultulu KB ve GD ya bakan bindirme fayları boyunca OligoMiyosen yaşlı formasyonları da üzerlemektedir. Bu birimlerde (Deliktaş ve Susuz formasyonları) KD-GB eksen gidişli, yer yer güneye devrik antiklinaller gözlenmektedir (Şekil 4F). Ayrıca, Tuztaşı formasyonunda yataya yakın bindirmeler ve kıvrımlar da gözlenmektedir (Şekil 4G). Bu durum KB - GD doğrultulu yaygın ve şiddetli bir sıkışma rejiminin bu dönemde de sürdüğünü göstermektedir. Bölgede bu dönemde önce olivinli bazalt ve andezit ve daha sonra andezitik ve bazaltik yaygın iki volkanizma (İğdeli formasyonu ve Erdavut volkaniti) gerçekleşmiştir. Yüksek potasyumlu volkanizma (Konak vd., 2001) ürünü bu volkanikler, Doğu Pontidlerdeki Neojen yaşlı çarpışma sonrası volkaniklerin (Aydın vd., 2008) havzadaki eşdeğeri olmalıdır.

\section{Geç Miyosen-Erken Pliyosen Dönemi}

Bütünüyle karasal çökel ve volkanitlerden oluşan Geç Miyosen-Erken Pliyosen yaşlı birimlerden İğdeli formasyonunda KB-GD doğrultulu KD ve GB ya eğimli haritalanamayacak boyutta normal faylar gözlenmektedir (Şekil 4H). Gerilmeli bir tektonik rejimi yansıtan bu dönemde yaygın andezitik ve dasitik volkanizma gerçekleşmiştir. Doğu Pontidlerde Orta Miyosen-Pliyosen yaşlı volkanitler, kuzeye yitimle ilişsili bir litosferik delaminasyon kökenli çarpışma sonrası ekstansiyonal rejimin ürünü olarak görülmektedir (Aydın vd., 2008). Eyüboğlu vd.(2012 ise inceleme alanın kuzeydoğusunda Uzundere yakınlarındaki Geç Miyosen yaşlı volkanitlerin yitimden çok, mafik alt kıta kabuğunun ergime ürünü olduğunu ileri sürmektedir. 


\section{Geç Pliyosen-Kuvaterner Dönemi}

Yatay konumlu karasal Geç Pliyosen-Kuvaterner çökelleri, Geç Miyosen çökelleri üzerinde açısal uyumsuzlukla bulunmaktadır. $\mathrm{Bu}$ birimler KD-GB doğrultulu ve KB-GD doğrultu atımlı faylardan etkilenmişlerdir. KD-GB doğrultulu faylar diğerlerine göre daha belirgindir. Bu etki günümüz de Görgün vd.' nin (2011) inceleme alanı ve çevresindeki deprem odak çözümlerinde görülmektedir (Şekil 5). Odak mekanizması çözümleri inceleme alanındaki fayların ters bileşenli KD-GB doğrultulu sol yanal doğrultu atımlı faylar olduğunu göstermektedir. Havzada günümüzde KD-GB doğrultulu fayların daha aktif olduğu transpressif bir rejim etkin durumdadır. Katmanların kıvrımlanmamış olduğu bu dönem bölgede Neotektonik evre olarak kabul edilmektedir (Koçyiğit vd., 2001).

Genelleştirilmiş stratigrafik kolon kesit ve fosil kapsamının yanı sıra, yukarıda anlatılan verilere göre, Oltu-Balkaya havzasındaki ve havza çevresindeki magmatik etkinlik verileri, tektonik dönemler ve evrim aşamaları Şekil 3' te birlikte sunulmuştur.

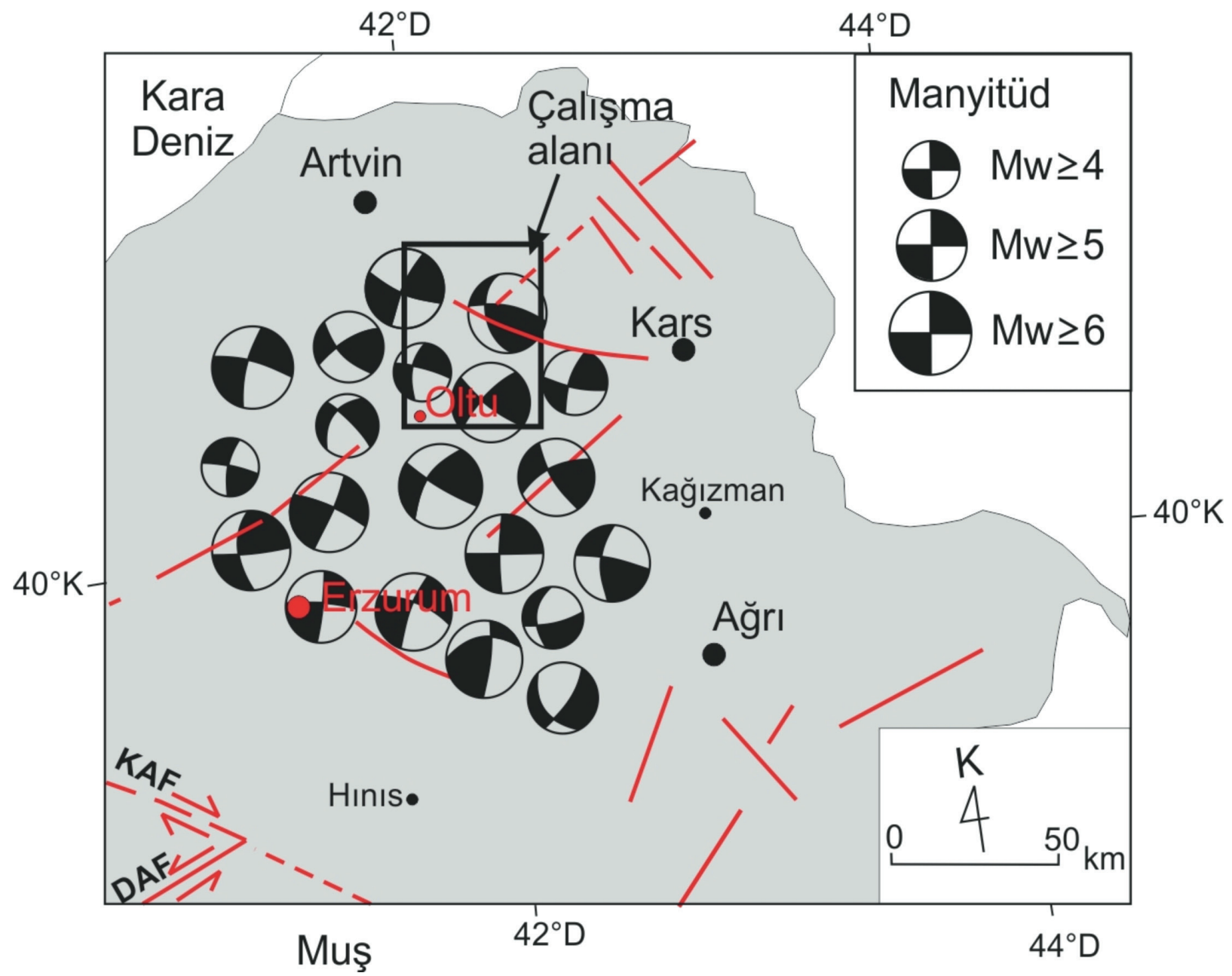

Şekil 5. Oltu-Balkaya havzası ve çevresindeki depremler ve odak mekanizma çözümleri (Görgün vd., 2011).

Figure 5. Earthquakes and their focal mechanisms in the Oltu Bakaya basin and its surrounding area (Görgün et al., 2011). 


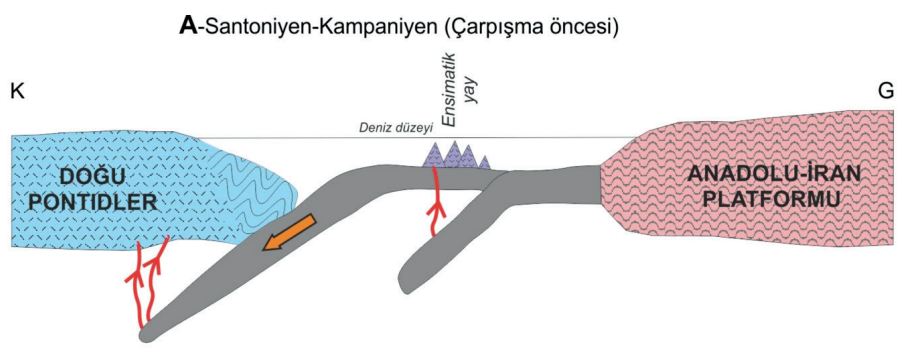

B- Maastrichtiyen(Çarpışma başlangıcı-soft collision)

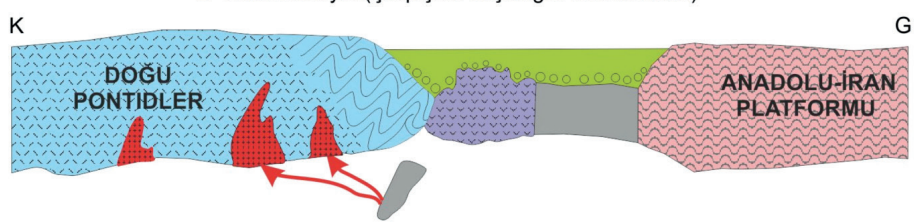

C-Orta Eosen(Çarpışma sona ermiş-soft collision, ama sıkışma devam ediyor)

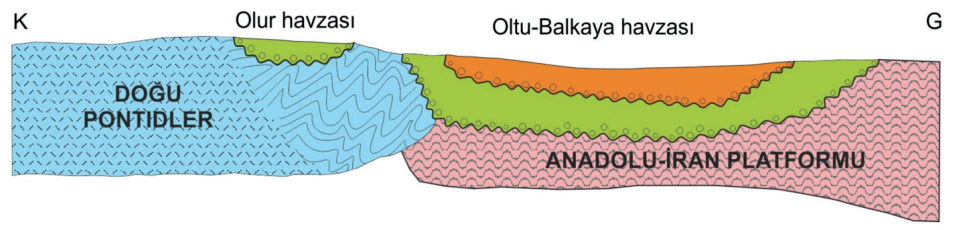

G
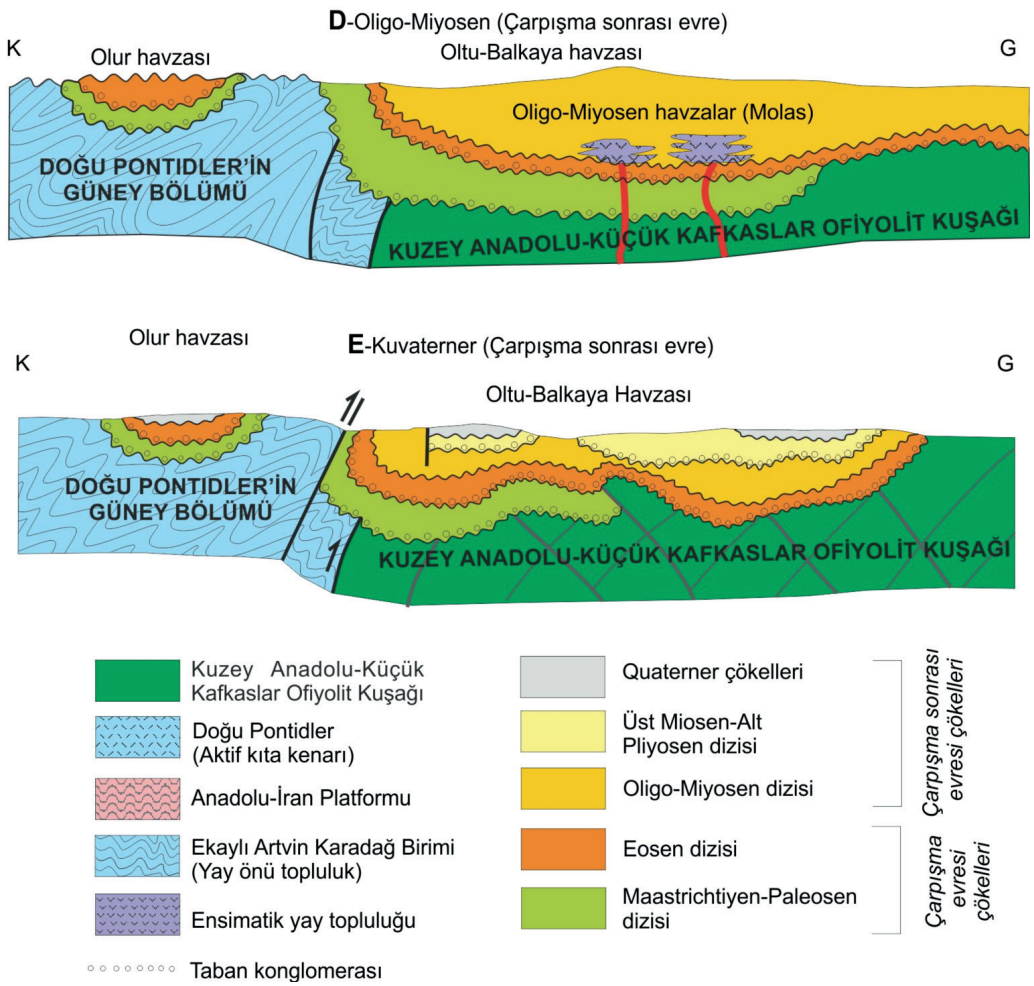

Şekil 6. Oltu-Balkaya havzasının Geç Kretase-Kuvaterner dönemindeki önemli yapısal evrim aşamalarını gösteren yalınlaştırılmış enine kesitleri.

Figure 6. Simplified cross-sections showing important stages of structural evolution of between Late Cretaceous and Quaternary. 


\section{SONUÇLAR}

İzmir Ankara-Erzincan Kenet kuşağı üzerinde Geç Kretase'den itibaren gelişen Oltu-Balkaya havzasının batısındaki Orta Anadolu havzaları, yay önü havzalar (Görür vd., 1984; Koçyiğit, 1991, Gökten, 1993) ve çarpışma havzaları (Erdoğan vd., 1996) olarak yorumlanmıştır. İzmir Ankara-Erzincan Kenet kuşağının doğuya uzantısı olan Küçük Kafkas Kenedi üzerinde ise Sosson vd. (2010) Paleosen'den itibaren çarpışma türü bir havzanın geliştiğini belirtmektedirler.

Oltu-Balkaya havzası ise, Pontid Yayı ve Anadolu-İran Platformu arasındaki Neo-Tetis'in kuzey kolunun ürünü olan üzerlemiş ofiyolitik birimler ve Pontid yayının güney bölümüne ait birimlerden oluşan bir mozaik temel üzerinde Üst Maastrihtiyen'den itibaren oluşmaya başlamıştır. Mozaik ve üzerindeki havza dolgusu arasında bölgesel bir uyumsuzluk vardır ve Oltu-Balkaya Havzasının temel kayaçları ile havza dolgusu çökellerinin arasındaki hem oluşum ortamı hem de uyumsuzluk şeklindeki stratigrafik ilişkisi, bu havzanın bir okyanus havzasının kalıntısı olamayacağını göstermektedir.

$\mathrm{Bu}$ durum, Oltu-Balkaya havzasinın çarpışma ile ilişkili bir havza ve Dickinson (1974) ve Miall (1981) in tanımlamalarına göre ise bu kuşak önünde veya çevresinde uzunlamasına gelişen bir ön çukurluk havzası olarak sinıflandırılmasına olanak verir.

Geç Maastrihtiyen-Erken Eosen dönemindeki birimlerin üzerinde ve içinde görülen değişik boyuttaki ofiyolit bindirmeleri, havzanın oluşumu sırasında da sıkışmanın yoğun olduğunu göstermektedir. Bu dönemde başlangıçta karasal ve sığ denizel çökeller, daha sonra görece derin deniz çökelleri çökelmiştir. Aynı dönemde Doğu Pontidlerde çarpışma ile yaşıt magmatizmadan söz edilmektedir (Boztuğ vd. (2006) ve daha doğuda Küçük Kafkaslarda Anadolu-İran Platformu'nun doğudaki uzantısı Güney Ermenistan ile Pontidlerin doğudaki uzantısı SomkhetoKarabakh'ın arasında da çarpışma ile yaşıt önülke niteliğinde bir havza gelişmiştir (Sosson vd., 2010). Bu veriler gözetildiğinde Oltu-Balkaya havzasının Geç Maastrihtiyen-Erken Eosen zaman aralığında çarpışma ile yaşıt önülke niteliğinde olduğu söylenebilir.

Orta Eosen'den itibaren Doğu Pontidlerde yaygın olan ve İzmir-Ankara-Erzincan Kened Kuşağını da kesen çarpışma sonrası magmatizma (Şengör ve Yılmaz, 1981; Genç ve Yılmaz, 1995; Y1lmaz ve Boztuğ, 1996; Y1lmaz vd., 1997; Okay ve Şahintürk, 1997; Boztuğ vd., 2001, 2002, 2003, 2004, 2006; Topuz vd., 2005; Arslan ve Aslan, 2006) bölgede Pontid Yay1 ve Anadolu-İran Platformu'nun son şiddetli çarpışmasının (hard-final collision) Orta Eosen'de tamamlanmış olduğunu göstermektedir. OltuBalkaya havzasında bu olayla ilişkili yükselmeyi kanıtlayan bir taban konglomerasıyla başlayan ve çarpışma sonrası Orta-Geç Eosen yaşlı çarpışma sonrası yüksek K lu kalkalkalen magmatizmanın eşlik etttiği (Konak vd., 2001) sığ denizel karakterli istif, çarpışma evresinden çarpışma sonrasına geçişi yansıtmaktadır. Oligo-Miyosen'de gelişen bölgesel bir transgresyonu izleyen karasal kırıntılilar ve sığ denizel karbonatlardan oluşan molas çökelimi ve eşlik eden yüksek potasyumlu volkanizma, çarpışma sonrası gelişen bir havza karakterini belirginleştirmektedir. Geç Miyosen başlangıcında gelişen yeni bir bölgesel transgresyon ile Geç Miyosen-Erken Pliyosen'de akarsu ortamından gölsel ortama kadar değişen çökeller ve andezitik-dasitik volkanizmanın oluşumu, havzanın çarpışma sonrası özelliğini sürdürdüğünü göstermektedir. Ancak aynı dönemde gelişmiş olan KKB-GGD doğrultulu DKD ve BGB ya eğimli normal faylar, havzada çarpışma sonrası yaklaşık DKD-BGB yönlü bir genişleme rejiminin varlığına bağlanabilir. 
Geç Pliyosen'den itibaren bölgede oluşan birimler kıvrımlanmamış ve Pliyosen-Kuvaterner çökellerini etkileyen KD-GB ve KB-GD uzanımlı doğrultu atımlı faylar bu dönemde etkin olan yaklaşık K-G doğrultulu sıkışma rejiminin ürünüdürler. İnceleme alanı ve çevresindeki deprem odak çözümleri (Görgün vd., 2011, Şekil 5).) havzada günümüzde ters bileşenli KD-GB doğrultulu sol yanal doğrultu atımlı fayların varlığ s1k1ştırmanın etkin olduğu bir rejimi işaret etmektedir.

Sonuç olarak Şekil 6' da sunulduğu gibi Oltu-Balkaya havzas1, Pontid Yayı ve Anadoluİran Platformu arasındaki Neo-Tetis Ofiyolit kenedi üzerinde, Neo-Tetis'in kuzey kolundan kaynaklanan üzerlemiş ofiyolitik birimler ve Pontid yayının güney bölümüne ait birimlerden oluşma bir mozaik üzerinde Geç Maastrihtiyen'den itibaren gelişen çarpışma ile (soft-collision, Draut and Clift (2001)) oluşmaya başlamıştır. Havza Geç Maasrihtiyen-Erken Eosen döneminde çarpışma ile çağdaş/eşyaşlı önülke niteliğinde iken Pontid Yayı ve Anadolu-İran Platformu'nun son çarpışmasının (hard-final collision, Draut and Clift (2001)) Orta Eosen'de tamamlanmasıyla Orta-Geç Eosende çarpışma evresinden çarpışma sonrasına geçişi yansıtan özellikler kazanmıştır. Oligo-Miyosen'de çarpışma sonrası havza karakteri belirginleşerek sürmüştür. Geç Miyosen-Erken Pliyosen'de havzada çarpışma sonrası genişlemeli rejim egemen olmuştur. Geç Pliyosenden itibaren K-G doğrultulu sıkışma rejiminin etkin olduğu havzada günümüzde ters bileşenli KD-GB doğrultulu sol yanal doğrultu atımlı fayların belirgin olduğu transpresif bir rejim etkindir. Havza içindeki aktif nitelikli KD-GB gidişli bindirme bileşenli sol yönlü doğrıultu atımlı fayların varlığı, Geç Pliyosenden itibaren havzayı denetleyen K-G yönlü sıkıştırma rejiminin kontrolünde gelişmiştir.

\section{KATKI BELIRTME}

$\mathrm{Bu}$ proje Cumhuriyet Üniversitesi Bilimsel Araştırma Projeleri Komisyonu Başkanlığı tarafindan M-462 numaralı bireysel araştırma projesi olarak desteklenmiştir. Yapıcı eleştirileri ve önerileriyle bu çalışmaya katkı koyan Prof. Dr. Halil GÜRSOY (Cumhuriyet Üniversitesi) ve Doç. Dr. Halil YUSUFOĞLU'na (MTA Genel Müdürlüğü) teşekkür ederiz.

\section{EXTENDED SUMMARY}

Oltu- Balkaya basin defined, first by Lange (1967). It has approximately $25 \mathrm{~km}$ in width and $50 \mathrm{~km}$ in length, which is located to the northeast of Erzurum province. It is also parallel to the general trends of the basement rock units, which are exposed around the basin.

In the previous studies (Lahn ve Romber, 1939; Baykal 1950; Tendam, 1951; Erentöz, 1954; Gattinger, 1955; Wedding, 1956; Nebert, 1963a,b; Engin and Engin, 1964; Lange, 1967; Altınl, 1969; Erentöz and Ketin, 1974; Akalın, 1978; Özdemir, 1981; Bulut et,al. 1989; Bozkuş, 1990; Bilgiç et al., 1995; Bozkuş, 1998; Yllmaz at, al, 2000; Konak et al., 2001; Konak and Hakyemez, 2008), a great deal of the tectonic and stratigraphic data have been presented. However, on the basis of these data, it is not possible to explain structural evolution of the basin as a whole. Therefore, in this study, it has been aimed to introduce the basin in detail, and also its structural evolutions in the regional geologic framework, after the field study.

The Oltu-Balkaya basin occurred on a mosaic, which is made up of fore-arc deposits of the Eastern Pontide Arc and ophiolites/ophiolitic with mélanges of the North Anatolian- Lesser Caucasus Suture.

The basin fill represents MaastrichtianQuaternary rock association. Atlular formation 
is made up of an alternation of MaastrichtianPaleocene turbiditic continental clastics and limestone (Fig. 4A), which overlie the Pre-Maastrichtian basic rocks with a clear unconformity (Yllmaz et al., 2000). The upper part of this unit passes Paleocene Bahçekışla formation laterally, which is made up of an alternation of conglomerate- sandstone in general, in the south of the basin (Konak et al., 2001). Bahçekışla formation is a product of marine and deltaic environment, which overlies the ophiolitic mélange at some places (Fig. 4B). However, the formation is tectonically thrusted over by the melange at some places (Fig. 4C). This unit passes transitionally to the Vişneli formation (Konak et al, 2001), which is represented by Early Eocene clastics and turbiditic rocks were deposited in gradually deepening marine.

Dağdibi formation (Bozkuş, 1993) rests on the Vişneli formation with a local unconformity, and it is made up of Middle- Late Eocene clastic rocks, which are products of shallow marine, including Nummulites and having a high energetic environment, with overlying volcanoclastic and volcanic rocks, in general. Karataş formation (Bozkuş, 1990) overlies the Dağdibi formation conformably, and it is made up of Middle-Upper Eocene (Konak ve Hakyemez, 2008) marine basaltic lavas and pyroclastic rocks, which are products of high potassium calc-alkaline volcanism, and lacustrine deposits in the lower and upper levels respectively.

Deliktaş formation (Bozkus, 1990) is represented by Late Oligocene- Early Miocene alternation of tuff, limestone and clastic rocks, in places, with intercalation of agglomerate and basalt, lies on Karataş and Vişneli formations unconformably respectively. It also reflects the characteristics of alluvial fan and braided river environments (Fig. 4D) and underlined by the
Vişneli formation tectonically at the Oltu town. The relationship between Deliktaş formation and ophiolitic melange has been defined as tectonic contact near from Aşăgl Çaml village to the North of Oltu town at previous studies (ex. Konak and Hakyemez,2008). However, during field study, it was observed that the Deliktas formation rested on the melange with a basal poligenetic conglomerate and unconformably at the same place (Fig. 4E).

Susuz formation (Bozkuş (1990) contains Upper Oligocene- Lower Miocene (Bilgiç et al., 1995; Konak et al., 2001) alternation of conglomerate-sandstone- claystone- limestone with coal intercalations, which reflecting continental environment, overlies Deliktaş formation conformably. In addition, Deliktaş formation passes also transitionally into the upper level to the Alaballk formation (Konak and Hakyemez, 2008), which is represented by the Early Miocene (Bayraktutan, 1994) yellow-green tuff, agglomerate and andesitic lavas.

The Oltu basin started to open by deposition of Upper Maastrichtian- Paleocene turbiditic continental clastics and reefal limestone after the compressional regime in the $N W$-SE direction, where it was dominant before Maastrichtian at the Oltu and surrounding area. As the Maastrichtian- Early Eocene units have folding in the NE-SW direction and tectonic contacts between basement rocks and the basin fill have also in NE-SW direction, reflecting $N W$ and SE vergents may be an evidence of the same compressional tectonic regime, which continued during Maastrichtian- Early Eocene.

During Middle- Late Eocene, shallow marine deposition with a basal conglomerate reflecting the land become a rise, occurred synchronizely with the post collisional calkalkaline volcanism (Karataş formation) having high 
potassium. The older units have obducted on the Middle-Late Eocene units along the NW and SE vergent overthrusts having $N E-S W$ direction in the surrounding area of the Oltu town.

After a regional transgression occurred during Oligocene, a molasse deposited, which include Oligocene- Middle Miocene continental clastics with shallow marine carbonates. PreMaastrichtian basement rocks obducted OligoMiocene formations, along the thrusts in the NE$S W$ direction and have NW and SE vergents. In addition, Oligo- Miocene units include overturned and horizontal folds plunging to the north in the NE-SW direction (Fig. 4F). It is possible to observe the overthrusts, cutting the folds plunging to the south and approximately horizontal overthrusts plunging to the north (Fig. 4G). This indicates that the intensive compressional tectonic regime went on during Oligo-Miocene in the NW-SE direction pervasively. During this time period, first olivine basalt and andesite (İgdeli formation) and then andesitic and basaltic volcanism (Erdavut Volcanics) occurred in the region. These volcanic rocks, which are products of volcanism with high potassium (Konak et al., 2001) should be equivalents of Neogene post collisional volcanics (Aydin et al., 2008) at the Eastern Pontides.

It is possible to observe small unmapped normal faults in the Late Miocene-Early Pliocene continental deposits and volcanic rocks in the $N W$-SE direction and dipping to NE and SW (Fig., 4H). Widespread andesitic and dasitic volcanism occurred during extensional tectonic regime in this time. In general, it is also accepted that Middle Miocene- Pliocene volcanics occurred as products of the extensional tectonic regime after the collision along the Eastern Pontides (Aydin et al., 2008; Eyüboğlu et al., 2012).

Continental and horizontal in setting deposits of Late Pliocene- Quaternary lie on
Upper Miocene deposits unconformably. These units were affected by the strike-slip faults in the $N E-S W$ and NW-SE directions. Faults in the NE$S W$ directions are prominent than others. It is possible to see this effect on the earthquake focal solutions of Görgün et al. (2011) at the study area and surroundings in Recent. The earthquake focal solutions show that the faults developed in the study area have left lateral strike-slip faults with reverse components in the NE-SW direction.

It is possible to suggest that the OltuBalkaya Basin evolved at five stages, on the basis of inner structure and the relationship between basement and cover rocks of the basin fill (Fig. 6).

1. Maastrichtian- Early Eocene: The OltuBalkaya Basin started to open depending on the collapse following the collision between the Eastern Pontide Arc and AnatolideTaurus Platform on the Pre-Maastrichtian tectonic mosaic related to the closing of the northern branch of Neotethys. In the beginning, a continental sequence derived from the clastic rocks, which are abundant at fore-arc associations, deposited in the basin. While thick mudstones with limestone alternation were deposited in the gradually deepening basin, syn-collisional granitoic magmatism, including Paleocene per aluminious leucogranite, developed from Kaçkar Mountains to the north of the OltuBalkaya Basin and also north of the Eastern Pontides (Boztuğ et al., 2006). In the Early Eocene, delta-marine clastic rocks were deposited.

2. Middle- Late Eocene: The basin uplifting depending on the compression had the $N W$ SE direction and Pre-Maastrichtian basic rocks thrusted along the NE-SW striking and $N W$ and SE dipping faults over the basin fill towards to the end of Early Eocene. Shallow 
marine deposition accompanied with MiddleLate Eocene post-collisional with high potassium calc-alkaline magmatism in the region (Konak et al., 2001).

3. Oligocene-Early/Middle Miocene: Aregional transgression occurred during Oligocene. A molasse, including continental clastic rocks and shallow marine carbonates, deposited in the Oligocene- Early/Middle Miocene time interval. Pre-Mastrichtian basement rocks were thrusted over Oligo-Miocene units along $N E-S W$ directed faults with northwest and southeast facing and folds having the axes in the NE-SW direction. Going on widespread and intensive compressional tectonic regime; the overthrusts, which are nearly horizontal dipping to the north, cut the folds verging to the south. The basin turned into a continental environment in the Miocene, where fluvial and lacustrine deposits lie on the Middle Miocene and older units with a regional unconformity. The region pursued its existence as the postcollisional setting, where the volcanism with high potassium was effective (Konak et al., 2001).

4. Late Miocene-Early Pliocene: In the region, where the extensional tectonic regime was effective, normal faults trending in the $N W$ $S E$ direction and dipping to the NE and SW were developed. In addition, postcollisional widespread andesitic and dasitic volcanism, which was a product of extensional tectonic regime, accompanied with the deposition in the region.

5. Late Pliocene- Quaternary: From the beginning of the Late Pliocene, NE-SW and NW-SE trending strike-slip faults have developed by the compression, approximately in the $\mathrm{N}-\mathrm{S}$ direction. In recent, a transpressive tectonic regime is dominant, where $N E-S W$ trending faults are more active in the basin.
The Oltu-Balkaya basin has started to open by the collision (soft-collision, Draut and Clift, 2001), since late Maastrichtian on a mosaic, composing of obducted ophiolitic units, derived from northern branch of Neotetyhs and the units of the southern parts of Eastern Pontide, and also on the ophiolitic suture between the Eastern Pontide and Anatolide-Tauride Platform. While The basin had the characteristics of syn-collisional foreland basin during Late Maastrichtian- Early Eocene, it gained the characteristics reflecting a transition from soft collision to post-collision (and/or hard-final collision, Draut and Clift, 2001) which completed in the Middle Eocene, between the Pontide Arc and Anatolide- Tauride Platform. post-collisional basinal development gradually became clear in the Oligo-Miocene. Postcollisional extensional tectonic regime became dominant in the Late Miocene- Early Pliocene in the basin. Since the Late Pliocene to Recent, NE-SW sinistrial strike-slip faults with reverse components occurred in the distinctive transpressive tectonic regime, under the $\mathrm{N}-\mathrm{S}$ directed compression

\section{DEĞİNILEN BELGELER}

Adamia, Sh. Belov, A., Kekelia, M. Shavishvili I., 1987. Palaeozoic tectonic development of the Caucasus and Turkey (Geotraverse G)H. Flugel, F.P. Sassi, P. Grecula (Eds.), Pre-Variscan and Variscan Events in the Alpine-Mediterranean Mountain Belts, Mineralia Slovaca, Alta Bratislava ( ), pp. 28-50

Akalın, L., 1978, Balkaya ve Sütküns (Erzurum) linyit sahaları etüdü: M.T.A. Rap. No: 224, Ankara.

Akin, H., 1979. Geologie, magmatismus und Lagerstattenbildung im ostpontischen Gebirge/ Türkei aus der Sicht der Plattentektonik. Geologische Rundschau 68, 253-283. 
Altınlı, İ.E., 1969, Oltu-Olur-Narman dolayının Jeolojik İncelemesi: TPAO Rap. No: 449, (yayımlanmamış).

Arslan, M., Aslan, Z., 2006. Mineralogy, petrography and whole-rock geochemistry of the Tertiary granitic intrusions in the Eastern Pontides, Turkey Journal of Asian Earth Sciences 27,177-193

Aydin, F., Karsl1, O., Chen, B., 2008. Petrogenesis of the Neogene alkaline volcanics with implications for post-collisional lithospheric thinning of the Eastern Pontides, NE Turkey. Lithos 104, 249266.

Baykal, F., 1950, Oltu-Göle-Ardahan-Çıldır bölgesinin jeolojik ana çizgisi:MTA Rap. No: 1928 (yayımlanmamış).

Bayraktutan, S., 1994, Narman-Gaziler bölgesinin Tersiyer>deki volkano-tektonik evrimi: 47. Türkiye Jeoloji Kurultayı, Bildiri Özleri, s. 104.

Bektaş,, O., Yılmaz, C., Taslı, K., Akdağ, K., Özgür, S., 1995. Cretaceous rifting of the eastern Pontides carbonate platform (NE Turkey): the formation of the carbonate breccias and turbidites as evidence of a drowned platform. Giornale di Geologia 57, 233-244.

Benda, L., 1971, Grundzüge einer pollenanalytischen Gliederung des Türkischen Jungtertiars. Beih. Geol. Jb., 113.

Bilgiç, T., Alişan, C, Tulu, N., 1995. The age and the microflora of the coal beds in the Balkaya region (Erzurum-Oltu), Second International Turkish Geology Workshop, Sivas, Turkey.

Bozkuş, C., 1990, Oltu-Narman Tersiyer havzası kuzeydoğusunun (Kömürlü) stratigrafisi. Türkiye Jeoloji Bull., 33, 47-56.

Bozkuş, C., 1993. Oltu-Narman Tersiyer Havzası Kuzeydoğusunun (Kömürlü) Tektoniği. Akdeniz Üniv. Müh. Fak. Dergisi 7, 65-80.

Bozkuş, C., 1998, Kuzeydoğu Anadoluda (OltuNarman Arası) Pontid / Anatolid Kenet Kuşağının Stratigrafisi ve Yapısal Evrimi. Pamukkale
Üniversitesi Mühendislik Fakültesi, Mühendislik Bilimleri Dergisi, 4/1-2, 487-499.

Boztuğ, D., Erçin, A.İ, Göç, D., Er, M., İskenderoğlu, A., Kuruçelik, M.K., Kömür, İ., 2001. Petrogenesis of the composite Kaçkar batholith along a north south geotraverse between Ardeşen (Rize) and İspir (Erzurum) towns, eastern Black Sea region, Turkey. Fourth International Turkish Geology Symposium (ITGS IV), Adana/Turkey, September 24 28, 2001, Abstracts, p. 210.

Boztuğ, D., Wagner, G.A., Erçin, A.İ., Göç, D., Yeğingil, Z., İskenderoğlu, A., Kuruçelik, M.K., Kömur, İ., Güngör, Y., 2002. Sphene and zircon fission-track geochronology unravelling subduction-and collision-related magma surges in the composite Kaçkar Batholith, Eastern Black Sea region, Turkey. 1st International Symposium of the Faculty of Mines (İTÜ) on Earth Sciences and Engineering, İstanbul, Turkey, May 16 18, 2002, Abstracts, p. 121.

Boztuğ, D., Kusçu, I., Erçin, A.I., Avc1, N., Şahin, S.Y., 2003. Mineral deposits associated with the pre-, syn- and post-collisional granitoids of the neoTethyan convergence system between the Eurasian and Anatolian plates in NE and Central Turkey. In: Eliopoulos, D. (Ed.), Mineral Exploration and Sustainable Development. Millpress, Rotterdam, pp. 1141-1144.

Boztuğ, D., Jonckheere, R., Wagner, G.A., Yeğingil, Z., 2004. Slow Senonian and fast PalaeoceneEarly Eocene uplift of the granitoids in the Central Eastern Pontides, Turkey: apatite fission-track results.Tectonophysics 382, 213-228.

Boztuğ, D., Erçin, A.I., Kuruçelik, M.K., Göç, D., Kömür, I., Iskenderoğlu, A.,2006. Geochemical characteristics of the composite Kaçkar batholith generate. Journal of Asian Earth Sciences 27, 286-302

Bulut, Y., Öğün,Y., Dümenci, S., Bozkuş, C., Taka, M. ve Öner, A., 1989, Tortum-Narman-Oltu-Olur dolayının jeolojisi ve kömür olanakları: MTA Rap. No: 8889 (yayımlanmamış). 
Cater, J.M.L., Hanna, S.S., Ries, A.C., Turner, P., 1991. Tertiary evolution of the Sivas Basin, Central Turkey. Tectonophysics 195, 29-46.

Dickinson, W.R., 1974. Plate tectonics and sedimentation. In: Dickinson, W.R. (Ed.), Tectonics and Sedimentation. Society of Economic Paleontologists and Mineralogists, pp. 1-27. Special Publications.

Draut, A.E., Clift, P.D., 2001. Geochemical evolution of arc magmatism during arc-continent collision, South Mayo, Ireland. Geology 29 (6), 543-546.

Engin, O., Engin, T., 1964, Hanege köyü (ErzurumOltu) ve civarındaki linyit ihtiva eden sahanın jeolojisi hakkında rapor: MTA Rap. No: 3548 (yayımlanmamış).

Ercan, T., Gedik, A., 1983. Pontidlerdeki volkanizma. Jeoloji Mühendisliği 18, 3-22.

Erdoğan, B., Akay, E., Uğur, M.Ş. 1996. Geology of the Yozgat region and evolution of collisional Çankırı Basin. International Geology Review: 38, $788-806$.

Erentöz, C., 1954, Oltu 31/4, Kars 32/3 ve Hasankale 48/2 1/100.000 ölçekli jeolojik paftalara ait memuar: MTA Rap. No: 2159 (yayımlanmamış).

Erentöz, C. ve Ketin, İ., 1974, 1/500.000 ölçekli Türkiye Jeoloji Haritası izahnamesi, Kars paftası: MTA yayını.

Eyuboglu, Y., Santosh M., Yi, K., Bektaş, O., Kwon, S., 2012. Discovery of Miocene adakitic dacite from the Eastern Pontides Belt (NE Turkey) and a revised geodynamic model for the late Cenozoic evolution of the Eastern Mediterranean region, Lithos 146-147, 218-232

Fenerci, M. 1994. Rudists from Maden (Bayburt) area, NW Turkey. Turkish Journal of Earth Sciences 3, $1-11$.

Gattinger, T.E., 1955, Kuzeydoğu Türkiye'de Çoruh ile Erzurum arasındaki bölgede yapılan jeolojik harita çalışmaları hakkında rapor: MTA Rap. No: 2379 (yayımlanmamış).
Gedikoğlu, A., 1979. Harşit (Giresun-Doğankent) granit karmaşığının jeokronolojik etüdü. Türkiye Jeoloji Bilimsel ve Teknik Kurultayı Bildiri Özleri Kitab1 33, 59-60.

Genç, Ş.C., Yılmaz, Y., 1995. Postcollisional Eocene magmatic activity of NW Anatolia: EUG VII, Strasbourg, Terra Abstracts, Terra Nova, 7, 1995, p. 181.

Gökten, E., 1993. Ulaş (Sivas) doğusunda Sivas havzası güney kenarının jeolojisi; Neotetis'in kuzey kolunun kapanması ile ilgili tektonik gelişim. In: 46th Geology Congress of Turkey, Abstracts, Ankara, p. 68.

Görgün, E., Kalafat, D., Kekoval1, K., 2011. Doğu Anadolu'nun sismotektonik yapısının deprem odak mekanizmalari yardımıyla yorumlanması. Türkiye Deprem Mühendisliği ve Sismoloji Konferans1 11-14 Ekim 2011, ODTÜ, Ankara.

Görür, N., Oktay, F.Y., Seymen, I., Şengör, A.M.C., 1984. Paleo-tectonic Evolution of the Tuzgölü Basin Complex, Central Turkey: Sedimentary Record of a Neo-Tethyan Closure. The Geological Evolution of the Eastern Mediterranean In: Dixon, J.E., Robertson, A.H.F. (Eds.),, vol.17. Geological Society, London, pp. 455-466. Special Publications.

Görür, N., Tüysüz, O., and Şengör, A. M. C., 1998. Tectonic Evolution of the Central Anatolian Basins. International Geology Review 40, 831850 .

Görür, N., Tüysüz, O. 2001. Cretaceous to Miocene Palaeogeographic evolution of Turkey: implications for hydrocarbon potential. Journal of Petroleum Geology 24, 1-28.

Gürsoy, H., 1989. Tectonics and stratigraphy of the Kelkit (Gümüşhane) region. Ph.D. thesis, Cumhuriyet University, Sivas, Turkey, 140p (in Turkish)

Kelling, G., Gökçen, S.L., Gökçen, N.S., Gökten, E., Bromley, A.J., 1989. Tectono-Sedimentary Evolution of a Neo-Tethyan Collisional 
Trough:Sivas-Refahiye Basin Central Turkey, 28th International Geological Congress, Washington, DC, USA, Abstracts, 2(3), pp. 171-172.

Koçyiğit, A., 1991. An example of an accretionary forearc basin from northern central Anatolia and its implications for the history of subduction of Neo-Tethys in Turkey. Geological Society of America Bulletin 103, 22-36.

Koçyiğit, A., 1996, Superimposed basins and their relations to the recent strike-sliop fault zone: a case study of the Refahiye superimposed basin adjacent to the North Anatolian Transform Fault, northeastern Turkey. International Geology Review, 38, 701-713.

Koçyiğit, A., Yılmaz, Y., Adamia, S., Kuloshvili, S., 2001. Neotectonics of East Anatolian Plateau (Turkey) and Lesser Caucasus: implications of transition from thrusting to strike-slipe faulting. Geodinamica Acta 14 (1-3), 177-195.

Konak, N., Hakyemez, H.Y., Bilgin, Z.R. and Bilgiç, T., 1995, Oltu-Olur-Şenkaya (Doğu Pontidler) jeolojisi. Maden Tetkik ve Arama Genel Müdürlüğü, Ankara (yayımlanmamış).

Konak, N., Hakyemez, H.Y., Bilgiç, T., Bilgin, R., Hepşen, N. ve Ercan, T. 2001. Kuzeydoğu Pontidlerin (Oltu-Olur-Şenkaya-NarmanUzundere-Yusufeli) Jeolojisi. Maden Tetkik ve Arama Genel Müdürlüğü Rapor No: 10489, Ankara (yayımlanmamış).

Konak N, Hakyemez Y.,2008. Geological map of Turkey in scale 1:100.000, Tortum H47 sheet (in Turkish). MTA publication, p. 95, Ankara.

Lahn, E. ve Romber, H., 1939, Balkaya linyit zuhuratının jeolojik tetkikatı ile mezkur havzada yapılan araştırma işleri ve işletme teklifleri hakkında rapor: MTA Rap. No: 765 (yayımlanmamış).

Lange, S., 1967, Erzurum-Oltu-Balkaya linyit havzasina ait jeolojik rapor: MTA. Rap. No: 122, Ankara. Lordkipanidze, M., Meliksetian, B., Djarbashian, R. 1989. Mesozoic-Cenozoic magmatic evolutionof the Pontiancrimean-Caucasus region.
Memoires de la Geologia France, Nouvella serie, 154,103-124.

Miall, A.D., 1981.Tectonic Setting and Basin Architecture Sedimentation and Tectonics in Alluvial Basins. In: Alluvial Sedimentary Basins, Miall, A.D. (Ed.), Special Publications, vol. 23. Geological Assocciations of Canada, London, pp. $1-33$.

Nebert, K., 1963a, Kömür ihtiva eden Sütkans bölgesinin (Vilayet Erzurum-Kaza Oltu) jeolojik yapısı ve kömür yataklarının jeolojisi hakkında rapor: MTA Rap. No:3232 (yayımlanmamış).

Nebert, K., 1963b, Henege köyü (Kaza Oltu, Vilayet Erzurum) bölgesinde yapılan kömür prospeksiyonu sonuçları hakkında rapor: MTA Rap. No: 3344. (yayımlanmamış).

Okay, A.I., Leven, E.J., 1996. Stratigraphy and paleontology of the Upper Paleozoic sequence in the Pulur (Bayburt) region, eastern Pontides.Turk. J. Earth Sci. 5, 145-155.

Okay A.I., Şahintürk, Ö., 1997. Geology of the Eastern Pontides. In: A.G. Robinson (ed.), Regional and Petroleum Geology of the Black Sea and Surrounding Region. Association of American Petroleum Geologists Memoir 68, 291-311.

Özdemir, İ., 1981, Oltu-Balkaya (Erzurum) kömürlü Neojen havzasının ekonomik jeolojisi: Ankara University Department of Engineering Geology, MS thesis, Ankara (Unpublished in Turkish).

Özsayar, T., Pelin, S., Gedikoğlu, A., 1981. Doğu Pontidler'de Kretase. KTÜ Yer Bilimleri Dergisi $1,65-114$.

Pelin,S., 1977, Alucra (Giresun) güneydoğusu yoresinin petrol olanakları bakımından jeolojik incelemesi: KTÜ yayını, No:87, 105 s., Trabzon.

Robinson, A.G., Banks, C.J., Rutherford, M.M., Hirst, J.P.P., 1995.Stratigraphic and structural development of the Eastern Pontides, Turkey. Journal of Geological Society London 152, 861872. 
Sosson, M., Rolland, Y., Danelian, T., Muller, C., Melkonyan, R., Adamia, S, Kangarli, T., Avagyan, A., Galoyan, G., 2010. Subductions, obduction and collision in the Lesser Caucasus (Armenia, Azerbaijan, Georgia), new insights. In: Sosson, M., Kaymakci, N., Stephanson, R., Bergarat, F., Storatchenoko, V. (Eds.), Sedimentary Basin Tectonics from the Black Sea and Caucasus to the Arabian Platform, vol. 340. Geological Society of London Special Publication, pp.329-352.

Şengör, A.M.C. and Yılmaz, Y., 1981. Tethyan evolution of Turkey: a plate tectonic approach. Tectonophysics 75, 181-241.Tendam, A., 1951, Balkaya linyit yatağının jeolojik haritasının revizyonuna ait rapor: M.T.A. Rap.No: 1887 , Ankara.

Tokel, S., 1977. Eocene calc-alkaline andesites and geotectonism in the Eastern Black Sea region (in Turkish). Türkiye Jeoloji Kurumu Bülteni 20, 49-54.

Topuz, G., Altherr, R., Kalt, A., Satir, M., Werner, O., Schwarz, W.H., 2004. Aluminous granulites from the Pulur complex, NE Turkey: a case of partial melting, efficient melt extraction and crystallisation. Lithos 72, 183-207.

Topuz, G., Altherr, R., Schwarz, W.H., Siebel, W., Satir, M., Dokuz, A., 2005. Post-collisional plutonism with adakite-like signatures: the Eocene Saraycik granodiorite (Eastern Pontides, Turkey). Contributions to Mineralogy and Petrology 150, 441-455.

Wedding, H., 1956, Balkaya linyit zuhuru, vilayet Erzurum, kaza Oltu, Pafta 31/2: MTA Rap. No: 2947 (yayımlanmamış).

Yılmaz, A., Adamia, S., Chabukiani, A., Chkhotua, T., Erdoğan, K., Tuzcu, S., Karabıyıkoğlu, M., 2000, Structural correlation of the southern Transcaucasus (Georgia)-eastern Pontides (Turkey). Geological Society, London, Special Publication 173, 171-182.
Yilmaz, A. and Yilmaz, H., 2006. Characteristic features and structural evolution of a post-collisional basin: the Sivas basin, Central Anatolia, Turkey. J Asian Earth Sci 27:164-176.

Y1lmaz, A., Adamia, SH., Y1lmaz, H., 2014. Comparisons of the suture zones along a geotraverse from the Scythian Platform to the Arabian Platform. Geoscience Frontiers 5, 855875 .

Yilmaz, S. and Boztuğ, D., 1996, Space and time relations of three plutonic phases in the. Eastern Pontides, Turkey. International Geology Review 38, 935-956.

Yilmaz, Y., 1972. Petrology and structure of the Gümüşhane granite and surrounding rocks, North-eastern Anatolia. PhD Thesis, University of London, 260p.

Yılmaz, Y., 1981. Sakarya kıtası güney kenarının tektonik evrimi. İstanbul Yerbilimleri 1 (1-2), 33-52.

Yılmaz, Y., Tüysüz, O., Yiğitbaş, E., Genç, Ş.C., Şengör, A.M.C., 1997. Geology and tectonic evolution of the Pontides. In: Robinson, A.G.(Ed.), Regional and Petroleum Geology of the Black Sea and Surrounding Region AAPG Memoir 68, pp. 183-226.

\begin{tabular}{|c|c|}
\hline Makale Geliş Tarihi & : 29 Nisan 2015 \\
\hline Kabul Tarihi & : 9 Kasim 2015 \\
\hline Received & : 29 April 2015 \\
\hline Acc & 9 November 201 \\
\hline
\end{tabular}


